\title{
High flux and fouling resistant flat sheet polyethersulfone membranes incorporated with graphene oxide for ultrafiltration applications
}

DOI:

10.1016/j.cej.2017.10.069

\section{Document Version}

Accepted author manuscript

Link to publication record in Manchester Research Explorer

\section{Citation for published version (APA):}

Leaper, S., Alberto, M., Vijayaraghavan, A., Holmes, S., Souaya, E. R., Badawy, M. I., Gorgojo, P., \& Ahmed Abdelkarim, A. (2017). High flux and fouling resistant flat sheet polyethersulfone membranes incorporated with graphene oxide for ultrafiltration applications. Chemical Engineering Journal, 334, 789-799. https://doi.org/10.1016/j.cej.2017.10.069

\section{Published in:}

Chemical Engineering Journal

\section{Citing this paper}

Please note that where the full-text provided on Manchester Research Explorer is the Author Accepted Manuscript or Proof version this may differ from the final Published version. If citing, it is advised that you check and use the publisher's definitive version.

\section{General rights}

Copyright and moral rights for the publications made accessible in the Research Explorer are retained by the authors and/or other copyright owners and it is a condition of accessing publications that users recognise and abide by the legal requirements associated with these rights.

\section{Takedown policy}

If you believe that this document breaches copyright please refer to the University of Manchester's Takedown Procedures [http://man.ac.uk/04Y6Bo] or contact uml.scholarlycommunications@manchester.ac.uk providing relevant details, so we can investigate your claim.

\section{OPEN ACCESS}




\section{Accepted Manuscript}

High flux and fouling resistant flat sheet polyethersulfone membranes incorporated with graphene oxide for ultrafiltration applications

Ahmed Abdel-Karim, Sebastian Leaper, Monica Alberto, Aravind Vijayaraghavan, Xiaolei Fan, Stuart M. Holmes, Eglal R. Souaya, Mohamed I. Badawy, Patricia Gorgojo

PII: S1385-8947(17)31783-7

DOI: https://doi.org/10.1016/j.cej.2017.10.069

Reference: CEJ 17853

To appear in:

\section{Chemical Engineering Journal}

Received Date: $\quad 23$ August 2017

Revised Date: $\quad 10$ October 2017

Accepted Date: $\quad 14$ October 2017

Please cite this article as: A. Abdel-Karim, S. Leaper, M. Alberto, A. Vijayaraghavan, X. Fan, S.M. Holmes, E.R. Souaya, M.I. Badawy, P. Gorgojo, High flux and fouling resistant flat sheet polyethersulfone membranes incorporated with graphene oxide for ultrafiltration applications, Chemical Engineering Journal (2017), doi: https:// doi.org/10.1016/j.cej.2017.10.069

This is a PDF file of an unedited manuscript that has been accepted for publication. As a service to our customers we are providing this early version of the manuscript. The manuscript will undergo copyediting, typesetting, and review of the resulting proof before it is published in its final form. Please note that during the production process errors may be discovered which could affect the content, and all legal disclaimers that apply to the journal pertain. 
High flux and fouling resistant flat sheet polyethersulfone membranes incorporated with graphene oxide for ultrafiltration applications

\section{Authors}

Ahmed Abdel-Karim ${ }^{1,4 a}$, Sebastian Leaper ${ }^{1 \mathrm{a}}$, Monica Alberto ${ }^{1}$, Aravind Vijayaraghavan ${ }^{2}$, Xiaolei Fan ${ }^{1}$, Stuart M. Holmes ${ }^{1}$, Eglal R. Souaya ${ }^{3}$, Mohamed I. Badawy $^{4}$, Patricia Gorgojo ${ }^{1 *}$

${ }^{1}$ School of Chemical Engineering and Analytical Science, The University of Manchester, Oxford Road, Manchester M13 9PL, UK.

${ }^{2}$ School of Materials, The University of Manchester, Oxford Road, Manchester M13 9PL, UK.

3 Chemistry Department, Faculty of Science, Ain Shams University, Abbassia, 11566 Cairo, Egypt

${ }^{4}$ Water Pollution Research Department, National Research Centre, 33 EL Bohouth St. (former EL Tahrir St.), P.O. 12622, Dokki, Giza, Egypt.

${ }^{a}$ Both authors contributed equally to this work

* Corresponding author: p.gorgojo@ manchester.ac.uk, tel: +44 (0) 161-30-64395

\section{Highlights}

1. PES/GO membranes were prepared in combination with various pore forming agents.

2. Higher flux and improved rejection were achieved with the addition of GO.

3. Synthetic solutions of protein and dyes were rejected efficiently at $1 \mathrm{bar}$.

4. Membrane fouling was reduced with the addition of GO. 


\section{Abstract}

In this work, graphene oxide (GO) was combined with polyethersulfone (PES) to form mixed matrix membranes (MMMs) for ultrafiltration of aqueous solutions. Also, the effect of adding various pore formers (poly(vinylpyrrolidinone (PVP), reverse triblock Pluronic (P31R1), and poloxamine Tetronic (T904)) to the dope solution was investigated. The prepared MMMs were characterised using various techniques, including Fourier-transform infrared spectroscopy, scanning electron microscopy and atomic force microscopy. It was found that the incorporation of $0.5 \mathrm{wt} \%$ of GO increased the flux from 2 to $13 \mathrm{~L} \mathrm{~m}^{-2} \mathrm{~h}^{-1}(\mathrm{LMH})$ and the rejection of bovine serum albumin (BSA) from 89.2 to $97 \%$ compared to benchmark PES membranes. SEM analysis revealed the increased pore size and porosity of the GO modified membranes, which contributed to the increased flux. The addition of pore formers further increased the flux compared to pure PES and also displayed synergistic effects with GO. The combination of T904 with $0.3 \mathrm{wt} \%$ GO increased the water flux significantly from 2 to 245 LMH and increased the rejection of acridine orange (from 40.5 to $48.4 \%$ ) and BSA (from 89.6 to $93.3 \%$ ), respectively. Also, fouling properties of the membranes were investigated with the parameters: flux recovery ratio $(F R R)$, total flux decline ratio $\left(R_{t}\right)$, reversible flux decline ratio $\left(R_{r}\right)$, and irreversible flux decline ratio $\left(R_{\text {ir }}\right)$, and improved anti-fouling properties were obtained with the addition of GO. This work shows the promise of GO as a performance-enhancing additive in MMMs for wastewater treatment.

Keywords: Graphene oxide; Membrane fouling, Mixed Matrix Membranes, Ultrafiltration membranes. 


\section{Introduction}

Today, despite its abundance on Earth, water is considered a scarce resource, owing to the fact that just $2.5 \%$ of the total amount is fresh water. Currently, agriculture, livestock and energy production account for $80 \%$ of all fresh water used. Meanwhile, as the human population grows and becomes increasingly industrial, demand for fresh water will continue to increase, putting further stresses on the sources currently available [1]. Furthermore, growing numbers of contaminants are entering water supplies as a result of human activities as well as salt water ingress from coastal regions. This poses public health and environmental risks which must be mitigated by the implementation of water treatment technologies such as disinfection, decontamination and desalination. Such technologies, however, can be very expensive and energy intensive and can require large quantities of chemicals which may produce toxic by-products. It is important that these issues are addressed at the outset so as not to replace one set of problems with another [2].

Membrane bioreactor (MBR) is a widely implemented technology for the treatment and reuse of wastewater in municipal and industrial plants. This technology offers significant advantages over conventional technologies. Among these advantages are higher chemical oxygen demand (COD) removal (as compared to conventional sludge processes) as well as the capability to operate at much higher concentrations of pollutants, no need for sedimentation, and the additional retention of certain chlorine resistant pathogens [3]. Despite its successful commercial implementation [4], MBR does suffer from some drawbacks, with

membrane fouling being the most significant of these. Consequently, several approaches have been applied to control this issue, including modification of the feed solution, modification of the surface of the membrane, changing the operating conditions and periodic cleaning, amongst others [5-7]. 
MBRs typically employ ultrafiltration (UF) as the main membrane separation process, in order to ensure the produced water is free from pathogens and microorganisms [8]. Asymmetric UF membranes can be prepared via non-solvent induced phase separation (NIPS) using a range of suitable polymers $[9,10]$. Among these materials, polyethersulfone (PES) has good chemical and mechanical stability [9], and is highly miscible with hydrophilic additives which can be used to improve the pore structure and increase the porosity of the membrane [10]. In addition, these additives can increase the hydrophilicity of the membrane which can, in turn, reduce the propensity of organic species to adhere to the surface. This can thereby improve the antifouling properties of the membrane, allowing for better long-term performance [11].

Graphene oxide (GO) is a well-known hydrophilic filler which exhibits many attractive properties such as high strength, low thickness, high flexibility and a negatively charged surface, offering water dispersability and good miscibility with polymers [12]. Lee et al. prepared polysulfone/GO mixed matrix membranes (MMMs) for treatment of wastewater with membrane bioreactor and found a higher resistance to both fouling and biofouling compared to the pure polymer as indicated by the increase in transmembrane pressure of 50 $\mathrm{kPa}$ after $50 \mathrm{hr}$ for the PSf/GO membrane compared to just $10 \mathrm{hr}$ for pure PES [13]. An improvement in membrane flux, and lower reversible and irreversible fouling was observed in similar systems elsewhere [14-17]. In other work, functionalized GO-polymer nanocomposites were developed for enhancing the biofouling and hydrophilic properties of ultrafiltration membranes [18]. In addition to GO's ability to increase the hydrophilic property of membranes (owing to its negatively charged functional groups), it has also been shown to increase the roughness and mechanical strength of the host polymer which also has an influence on antifouling properties and performance [19]. 
Pore forming agents such as PVP and PEG $[14,20]$ were also proposed to improve the property of membranes (e.g. hydrophilicity and flux). Recently, novel copolymers like T904 and P31R1 have also been shown to improve the properties of PES membranes based on our previous work [10]. T904 and P31R1 copolymers contain polypropylene and polyethylene oxide segments. The former gives rise to strong hydrophobic interactions with the PES matrix and the latter creates hydrophilic surfaces in the prepared membranes [10]. However, the influence of these additives on nanocomposite polymer-membranes is not yet fully understood. It is clear that performance enhancements can be achieved with the addition of nanomaterials such as graphene oxide and pore forming agents separately, but the combination of these two additives has not yet been systematically studied.

Chemical pollutants such as bovine serum albumin (BSA), acridine orange (AO) and sunset yellow (SY) dyes were used as model compounds for testing the membrane performance. In this work, the use of GO nanosheets to tackle the fouling issue suffered by pure PES polymer membranes was first explored, followed by the combination of GO and pore forming agents to further enhance the flux of such membranes. Our postulation was that the barrier layer would be more hydrophilic after the addition of GO as a result of the presence of carboxylic acid (-COOH) and hydroxyl (-OH) functional groups, thus mitigating the interaction between the foulant and the membrane surface and so reducing fouling. This effect was first investigated in simple binary systems of PES and GO of varying ratios. In addition to this, novel pore forming agents, P31R1 and T904 were used to increase the porosity and thereby improve the overall performance of the membranes. For the first time, combinations of GO with pore forming agents P31R and T904 were prepared and tested for ultrafiltration in order to identify possible synergistic effects. 


\section{Experimental}

\subsection{Materials}

Commercial grade Polyethersulfone Ultrason E6020P $\left(\mathrm{MW}=58,000 \mathrm{~g} \mathrm{~mol}^{-1}\right.$ and glass transition temperature, $\mathrm{T}_{\mathrm{g}}=225^{\circ} \mathrm{C}$ ) was provided by BASF, Ludwigshafen, Germany. $\mathrm{N}, \mathrm{N}$ - dimethylformamide (DMF) was used as the solvent for the preparation of the casting dope solutions, and bovine serum albumin $\left(\mathrm{BSA}, \mathrm{MW}=66,500 \mathrm{~g} \mathrm{~mol}^{-1}\right)$, sunset yellow $(\mathrm{SY}$, $\left.\mathrm{MW}=452.4 \mathrm{~g} \mathrm{~mol}^{-1}\right)$, and acridine orange $\left(\mathrm{AO}, \mathrm{MW}=265.4 \mathrm{~g} \mathrm{~mol}^{-1}\right)$ were used as model rejection compounds for the filtration experiments. Graphite powder (Naturegraphit $\mathrm{GmbH}$, Germany) was used for the preparation of graphene oxide. Potassium permanganate $\left(\mathrm{KMnO}_{4}\right.$; $99 \%)$, hydrogen peroxide $\left(\mathrm{H}_{2} \mathrm{O}_{2} ; 30 \%\right.$ aqueous solution), sodium hydroxide $(\mathrm{NaOH})$, sulphuric acid $\left(\mathrm{H}_{2} \mathrm{SO}_{4} ; 98 \%\right)$, nitric acid $\left(\mathrm{HNO}_{3} ; 68 \%\right)$ and hydrochloric acid $(\mathrm{HCl} ; 37 \%)$ were purchased from Sigma Aldrich, UK and used as received. Deionized water (DI) used in this study was produced by a Milli-Q integral system (Merck Millipore, Ireland). PVP with a molecular weight (MW) of 40,000 $\mathrm{g} \mathrm{mol}^{-1}$ (Sigma Aldrich, Germany), Tetronic T904 (BASF, Germany) and Pluronic 31R1 (BASF, Germany) were used as the pore forming agents.

\subsection{Synthesis and characterisation of Graphene Oxide}

GO nanosheets were prepared from graphite powders by a modified Hummers' method [19, 20], and characterized using Raman spectroscopy and scanning electron microscopy (SEM) [21, 22].

Raman spectra of GO samples were recorded from 200 to $2000 \mathrm{~cm}^{-1}$ on a Renishaw 2000 Confocal Raman Microprobe InVia Reflex microscope (Renishaw Instruments, 
England) using a 290-nm argon ion laser at lower than $10 \mathrm{~mW}$ power. GO samples were spin-coated at $3000 \mathrm{rpm}$ on silicon/silicon dioxide wafers before the analysis.

SEM was used to visualize the GO flakes, which were sputter-coated with Pt. This was performed using a Zeiss Ultra with an InLens detector and an accelerating voltage of 15 $\mathrm{kV}$.

\subsection{Preparation of asymmetric PES/GO mixed matrix membranes}

Hybrid membranes were fabricated from dope solutions of PES dissolved in DMF containing various amounts of graphene oxide and/or pore formers by the non-solvent induced phase separation (NIPS) method. The composition and labelling of PES and PES/GO MMMs is given in Table 1. Prior to the preparation of the casting solutions, PES was dried at $105{ }^{\circ} \mathrm{C}$ for $2 \mathrm{~h}$, and freeze-dried GO was dispersed into DMF and then sonicated in a sonication bath (Decon FS100b) for $1 \mathrm{~h}$. DMF was selected as the solvent for the preparation of the casting solutions due to a longer lasting dispersability of GO ( $\geq 400$ hours [23]) as compared to other solvents (e.g. dimethyl sulfoxide, DMSO ). Pure PES and PES/GO hybrid membranes were also prepared and used as controls to assess the effect of adding pore forming agents. To prepare the solutions, $1 \mathrm{~g}(20 \mathrm{wt} \%)$ of PES was dissolved in a $4 \mathrm{~g}$ solution of DMF containing various quantities of GO by continuous stirring for $24 \mathrm{~h}$ at $24 \pm 2{ }^{\circ} \mathrm{C}$ inside tightly sealed glass vials. The GO wt $\%$ values (i.e. $0.1,0.2,0.3,0.5$ and $1 \%$ ) were measured w.r.t. the polymer weight and so $20 \%$ of these values give the $\mathrm{GO}$ wt $\%$ w.r.t. the whole solution weight. For example, the $0.1 \mathrm{wt} \% \mathrm{GO}$ solution (w.r.t. the polymer) is the same as $0.02 \mathrm{wt} \%$ w.r.t. the whole solution, as is depicted in Table 1. For the membranes containing pore forming agents, the wt $\%$ of the pore forming agents was measured w.r.t. the whole solution weight. These were added to the base polymer and then the same dissolution procedure was followed. Afterwards, the solution was left 4 hours without stirring for the 
removal of air bubbles, and was subsequently cast onto a smooth glass plate and uniformly spread with the aid of an automatic film applicator (Sheen $1133 \mathrm{~N}, \mathrm{UK}$ ) with a $200 \mu \mathrm{m}$ gate height and a shear rate of $50 \mathrm{~mm} \mathrm{~s}^{-1}$. The time between casting the solution and transferring it into the DI water coagulation bath was $10 \mathrm{~s}$. The membrane peeled off from the glass plate and was washed with fresh DI water, dried at room temperature, and stored until required for testing and characterisation. The size of the cast membranes was approximately $100 \times 300$ $\mathrm{mm}$.

Table 1. Prepared membranes and compositions of casting solutions. The GO wt $\%$ values (i.e. $0.1,0.2,0.3,0.5$ and $1 \%$ ) were measured w.r.t. the polymer weight and so $20 \%$ of these values give the $\mathrm{GO}$ wt $\%$ w.r.t. the whole solution weight as shown in the table.

\begin{tabular}{clcccc}
\hline $\begin{array}{c}\text { Entry } \\
\text { code }\end{array}$ & Membrane & $\begin{array}{c}\text { PES } \\
(\mathbf{w t} \%)\end{array}$ & $\begin{array}{c}\text { DMF } \\
(\mathbf{w t} \%)\end{array}$ & $\begin{array}{c}\text { GO } \\
(\mathbf{w t} \%)\end{array}$ & $\begin{array}{c}\text { Pore forming } \\
\text { agent (wt\%) }\end{array}$ \\
\hline M1 & PES & 20 & 80.0 & 0 & \\
M2 & PES/0.1GO & 20 & 79.98 & 0.02 & \\
M3 & PES/0.2GO & 20 & 79.96 & 0.04 & \\
M4 & PES/0.3GO & 20 & 79.94 & 0.06 & - \\
M5 & PES/0.5GO & 20 & 79.9 & 0.1 & \\
M6 & PES/1.0GO & 20 & 79.8 & 0.2 & \\
\hline M7 & PES/0.1GO/3PVP & 20 & 76.98 & 0.02 & \\
M8 & PES/0.3GO/3PVP & 20 & 76.94 & 0.06 & PVP (3) \\
M9 & PES/0.5GO/3PVP & 20 & 76.9 & 0.1 & \\
\hline M10 & PES/0.1GO/5P31R1 & 20 & 74.98 & 0.02 & \\
M11 & PES/0.3GO/5P31R1 & 20 & 74.94 & 0.06 & P31R1 (5) \\
M12 & PES/0.5GO/5P31R1 & 20 & 74.9 & 0.1 & \\
\hline M13 & PES/0.1GO/5T904 & 20 & 74.9 & 0.02 & \\
M14 & PES/0.3GO/5T904 & 20 & 74.94 & 0.06 & T904 (5) \\
M15 & PES/0.5GO/5T904 & 20 & 74.9 & 0.1 & \\
\hline & & & & & \\
\hline
\end{tabular}




\subsection{Characterization of PES/GO Mixed Matrix Membranes (MMMs)}

Attenuated total reflection Fourier transform infra-red spectroscopy (ATR-FTIR) was carried out using an Ids Nicolet Is5 instrument (Thermo Scientific, UK) using a Ge crystal over the wavenumber range of $650-4000 \mathrm{~cm}^{-1}$ and a step size of $0.5 \mathrm{~cm}^{-1}$.

Raman spectra were obtained using a Renishaw Raman imaging instrument (inVia) equipped with a Leica microscope and a charge coupled device (CCD) detector. The excitation wavelength was $290 \mathrm{~nm}$ and the laser power was kept below $10 \mathrm{~mW}$ to avoid the thermal degradation of the membranes. The membrane samples were prepared by spin coating the GO + DMF + PES dispersions on glass slides and leaving them to dry under vacuum at room temperature. 3-4 mapping points were measured for each sample.

The morphology of top surfaces and cross sections of the prepared membranes were examined with SEM (QUANTA FEG250, USA) at an accelerating voltage of $20 \mathrm{kV}$. For the preparation of cross sectional images, pieces of the membranes were immersed in liquid nitrogen for 60-90 s and fractured. Once dried and mounted onto SEM stages, these samples were sputtered with platinum (5-6 nm Pt layer) using an MTM 10 Thickness Monitor (Cressington, USA) to provide electrical conductivity. Top surfaces were also sputtered with platinum.

Contact angle measurements were conducted on the surfaces of flat sheet membranes with DI water utilizing an Attension Theta optical tensiometer (Biolin Scientific, UK) via the sessile drop method [24]. The contact angle was measured immediately after the DI water

was dropped onto the membrane surface, which reflects the natural wettability of the material. Briefly, a drop of DI water was deposited using a microsyringe with a stainless steel needle (Hamilton microsyringe) at room temperature. The software was set to record $30 \mathrm{fps}$ for $20 \mathrm{~s}$, and the water contact angle was recorded $5 \mathrm{~s}$ after the water droplet had touched the sample surface. 
Atomic force microscopy (AFM) was carried out using a Fastscan microscope (Bruker, USA). The measurements were conducted over an area of $30 \mu \mathrm{m} \times 30 \mu \mathrm{m}$ using tapping mode at room temperature and in an air atmosphere. The surface roughness parameters were reflected in terms of the average roughness $(R a)$, the root mean square of the $\mathrm{Z}$ data $(R q)$ and the mean difference between the highest peaks and the lowest valleys $(R z)$ calculated using Nanoscope analysis software version 1.5.

The membrane porosity was determined through a gravimetric method reported elsewhere $[10,15]$. Briefly, the dried membranes were immersed in the DI water for $24 \mathrm{~h}$ at room temperature (RT). Thereafter, samples were carefully taken out, wiped using tissue paper to remove excess water from the surface, and weighed (analytical balance KERN ABJ 120-4NM, Germany). Afterwards, samples were placed in a vacuum oven at $60{ }^{\circ} \mathrm{C}$ for $8 \mathrm{~h}$ then weighed. The porosity, $\varepsilon$, was calculated using Equation 1:

$$
\varepsilon=\frac{\frac{W_{w}-W_{d}}{\rho_{w}}}{\frac{W_{w}-W_{d}}{\rho_{w}}+\frac{W_{d}}{\rho_{p}}} \times 100
$$

where $W_{w}$ is the weight of the wet membrane, $W_{d}$ is the weight of the dry membrane, $\rho_{w}$ and $\rho_{p}$ are the density of water $\left(0.998 \mathrm{~g} \mathrm{~cm}^{-3}\right)$ and polymer $\left(1.37 \mathrm{~g} \mathrm{~cm}^{-3}\right)$, respectively.

The antifouling properties of the prepared membranes were assessed via a protein adsorption test (static BSA adsorption test). For the experiment, a $4 \mathrm{~cm}^{2}$ piece of each membrane was kept in $10 \mathrm{~mL}$ of BSA solution $\left(1.0 \mathrm{~g} \mathrm{~L}^{-1}\right)$ to attain adsorption-elution equilibrium at room temperature and after $24 \mathrm{~h}$ the sample was taken out of the solution. The initial and the final concentrations of protein in the solution were determined using UV-Vis spectrophotometry at a wavelength of $280 \mathrm{~nm}$. The BSA adsorption capacity of the membrane was calculated from the initial concentration of both feed and final BSA adsorbate using Equation 2: 


$$
\text { BSA adsorption }(\%)=\left(\frac{\mathrm{C}_{f}-\mathrm{C}_{i}}{C_{f}}\right) \times 100 \quad \text { Eq. } 2
$$

where $C_{i}$ and $C_{f}$ are the initial and final concentrations of the protein solution, respectively.

The surface free energy $\left(\Delta G_{s}\right)$ of the membranes was calculated using the Young Dupre equation (Equation 3) [24].

$$
-\Delta G_{s}=(1+\cos \theta) \gamma_{L}^{T}
$$

Eq. 3

where $\theta$ is the water contact angle value and $\gamma_{L}^{T}$ is the surface tension of water $\left(72.8 \mathrm{~mJ} \mathrm{~m}^{-2}\right)$.

\subsection{Filtration performance and fouling study of membranes}

Membrane permeation flux, retention, and antifouling properties were evaluated using a dead-end stirred cell (Sterlitech HP4750). The cell was pressurised with nitrogen gas at 1 bar and the filtration experiments were conducted at $20 \pm 1{ }^{\circ} \mathrm{C}$. First of all, pure water permeability (PWP) was measured by passing $200 \mathrm{~mL}$ of DI water through the membrane and measuring the permeate volume after 30 minutes. The PWP was then calculated using Equation 4:

$$
P W P=\frac{V}{A t P}
$$

Eq. 4

where $V$ is the permeate volume $(\mathrm{L}), A$ is the effective membrane area $\left(12.56 \times 10^{-4} \mathrm{~m}^{2}\right), t$ is the operation time (h), and $P$ is the operation pressure (bar).

Filtrations of BSA, SY, and AO aqueous solutions were performed also using a deadend stirred cell. The concentration of these compounds in the aqueous feed solutions was 
$1000 \mathrm{ppm}(\mathrm{pH}=6.1), 68 \mathrm{mg} \mathrm{L}^{-1}$, and $200 \mathrm{mg} \mathrm{L}^{-1}$, respectively. The rejection was determined using Equation 5:

$$
R=1-\frac{C_{p}}{C_{f}} \times 100
$$

Eq. 5

where $C_{p}$ is the concentration in the permeate solution and $C_{f}$ is the concentration in the feed solution. These values were obtained from permeate and feed solutions via UV-Vis at wavelengths of 280, 490, and $490 \mathrm{~nm}$ for BSA, SY, and AO, respectively.

In order to assess the anti-fouling performance of the membranes, the following protocol was followed: first, the pure water flux was measured at 1 bar $\left(J_{1}\right)$; subsequently, the BSA aqueous solution was used as the feed, also at 1 bar and the foulant solution flux was measured for $30 \min \left(J_{p}\right)$. Finally, the pure water flux was measured again after $30 \mathrm{~min}$ of being flushed at a pressure of 1 bar $\left(J_{2}\right)$. The membrane was assessed by four parameters including the flux recovery ratio $(F R R)$, the total flux decline ratio $\left(R_{t}\right)$, the reversible flux decline ratio $\left(R_{r}\right)$, and the irreversible flux decline ratio $\left(R_{i r}\right)$. The flux recovery ratio was calculated using Equation 6, and $R_{t}, R_{r}$ and $R_{i r}$ using Equations 7, 8 and 9, respectively:

$$
\begin{aligned}
& \operatorname{FRR}=\left(\frac{J_{2}}{J_{1}}\right) \times 100 \\
& R_{t}=\left(1-\frac{J_{p}}{J_{1}}\right) \times 100
\end{aligned}
$$




$$
\begin{array}{ll}
R_{r}=\left(\frac{J_{2}-J_{p}}{J_{1}}\right) \times 100 & \text { Eq. } 8 \\
R_{\text {ir }}=\left(\frac{J_{1}-J_{2}}{J_{1}}\right) \times 100 & \text { Eq. } 9
\end{array}
$$

where $J_{1}$ is the pure water flux before the fouling test, $J_{2}$ is the pure water flux after fouling and $J_{p}$ is the flux of the foulant solution.

\section{Results and discussion}

\subsection{Characterization of graphene oxide nanosheets}

Details of GO characterization using Raman and SEM can be found in the supporting information (SI) and in the following sections.

\subsection{Characterization of mixed matrix membranes}

Figure 1 depicts the chemical structure of PES and GO and the possible formation of hydrogen bonds between PES and GO [15]. It is important to know the nature of the interactions between the polymer and GO nanosheets, as this may affect the overall morphology and performance of the membranes. 


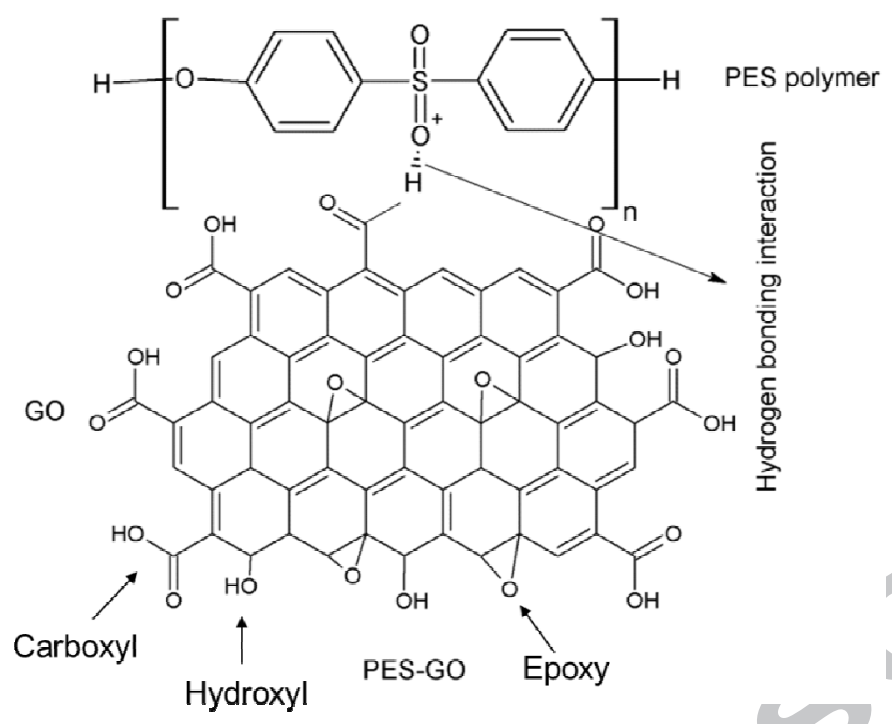

Figure 1. Schematic presentation for the hydrogen bonding interaction between sulfone $\left(\mathrm{SO}_{2}\right)$ groups of the PES chain and - $\mathrm{COOH}$ groups of $\mathrm{GO}$ in the hybrid membranes.

ATR-FTIR analysis was carried out to confirm the presence of GO in addition to tracking any change in the chemistry of the fabricated membranes. Figure 2 shows the FTIR spectra of pure PES, PES/0.5GO, PES/0.3GO/3PVP, PES/0.3GO/5P31R1, and PES/0.3GO/5T904 membranes (Figure 2a), and GO (Figure 2b). The characteristic peaks of GO are found at 1090, 1248, 1600 and $1750 \mathrm{~cm}^{-1}$ and a broad band from $2990-3600 \mathrm{~cm}^{-1}$ which are assigned to alkoxy $\mathrm{C}-\mathrm{O}$ stretching vibrations, epoxy $\mathrm{C}-\mathrm{O}$ stretching vibrations, $\mathrm{C}=\mathrm{C}$ stretching in the aromatic ring, $\mathrm{C}=\mathrm{O}$ carboxyl stretching and $\mathrm{O}-\mathrm{H}$ stretching, respectively [25]. For PES/GO MMMs, the peaks at 1242 and $1142 \mathrm{~cm}^{-1}$ can be attributed to the stretching vibrations of asymmetric and symmetric $S=O$, respectively [26]. The strong absorptions in 1480-1600 $\mathrm{cm}^{-1}$ regions are associated with the benzene ring skeletal stretching mode.

The broad band between 3000 and $3600 \mathrm{~cm}^{-1}$ observed in the PES/0.5GO membrane were related to the $\mathrm{OH}$ groups of $\mathrm{GO}$ and confirm the presence of $\mathrm{GO}$ in the PES matrix. However, for lower loadings of GO (not shown), these features were not observed. After the 
addition of the pore formers (PVP, P31R1, and T904), the broad band was observed for PESGO-PVP and broad peaks in the region 2800-3000 for PES-GO-PVP and PES-GO-T904 membranes. This confirms the presence of unreacted $\mathrm{OH}$ groups from $\mathrm{GO}$ in these two membranes and suggests interaction between the additive P31R1 and GO through OH groups in the membrane PES-GO-P31R1 (as the broad bands are not present).

a)

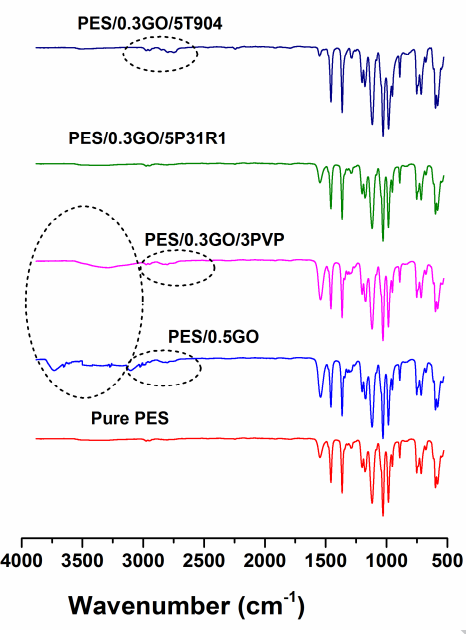

b)

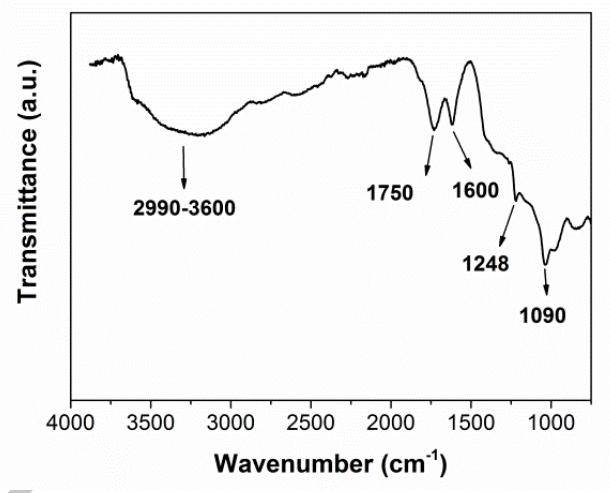

Figure 2. FTIR spectra of a) pure PES (M1), PES/0.5GO (M5), PES/0.3GO/3PVP (M8), PES/0.3GO/5P31R1 (M11), and PES/0.3GO/5T904 (M14) membranes, and b) GO. Y axis is transmittance for both graphs.

Raman spectra for GO, pure PES and PES-GO membranes are presented in Figure 3. The significant structural changes occurring during the chemical processing from pristine graphite to GO are reflected in their Raman spectra. There are two distinctive bands, namely, the $\mathrm{D}$ and $\mathrm{G}$ bands. The $\mathrm{D}$ and $\mathrm{G}$ bands are obtained at $1351 \mathrm{~cm}^{-1}$ and $1606 \mathrm{~cm}^{-1}$, respectively. The $\mathrm{G}$ band provides information on the in-plane stretching vibration of symmetric $\mathrm{C}-\mathrm{C}$ bonds. The $\mathrm{D}$ band indicates disruption of the symmetrical hexagonal graphitic lattice by internal structural defects, edged effects and dangling bonds [27]. The $\mathrm{I}_{\mathrm{D}} / \mathrm{I}_{\mathrm{G}}$ ratio is used to assess the structural changes in graphene based materials. The intensity ratio $I_{D} / I_{G}$ obtained for GO in this work is 1.05 which suggests high number of $\mathrm{sp}^{2}$ domains in the graphene oxide structure [28]. 
The bands at 1072 and $1109 \mathrm{~cm}^{-1}$ are attributed to symmetric and asymmetric stretching vibrations of $\mathrm{O}=\mathrm{S}=\mathrm{O}$ groups. The strong band at $1145 \mathrm{~cm}^{-1}$ is ascribed to symmetric C-O-C stretching, and bands at $1590,1610 \mathrm{~cm}^{-1}$ correspond to a vibration of phenyl rings [15]. Broad peaks are observed at $1350 \mathrm{~cm}^{-1}$ and $1600 \mathrm{~cm}^{-1}$ for membrane M5 (PES/0.5GO), which is characteristic of the D and G bands for GO nanosheets [15]. The D band is absent in the spectrum of membrane M1 (pure PES) and becomes higher in intensity as the amount of GO increases for the hybrid membranes. Thus, these results confirm the presence of GO in the hybrid membranes.

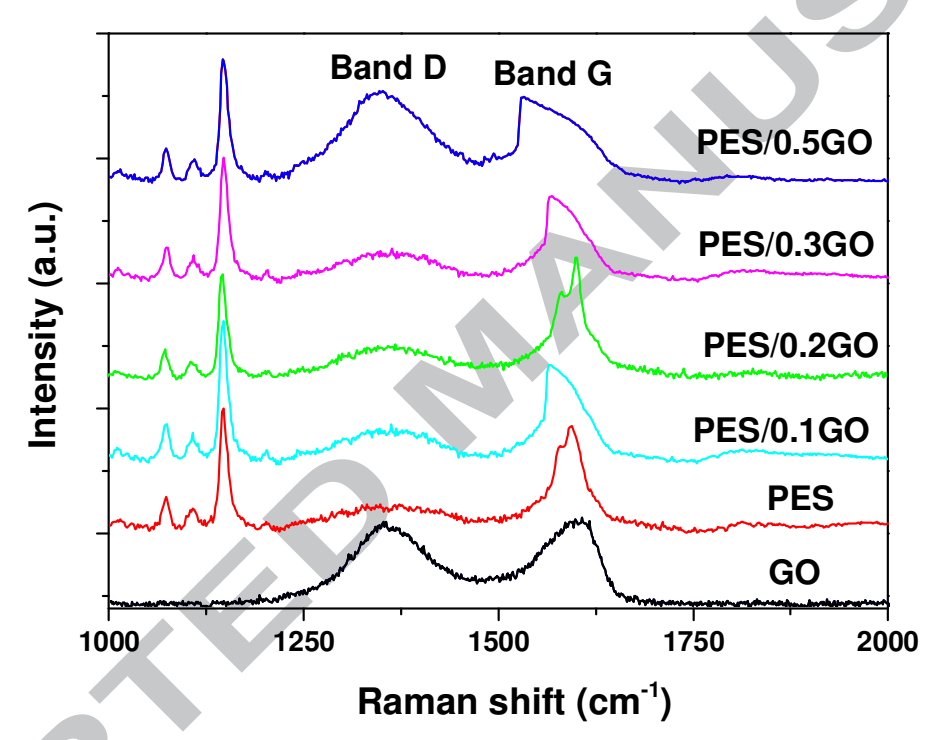

Figure 3. Raman spectra for GO and PES-GO MMMs (M1-M5) in the range from 1000$2000 \mathrm{~cm}^{-1}$

It was found that the hydrophilicity of the membranes was affected by the additions of GO and pore forming agents. Water contact angle measurements were investigated as shown in Figure 4. In general, a lower contact angle indicates that the membrane surface is more hydrophilic in nature. As presented in Figure 4, the static contact angle decreased with the addition of the GO into the polymer matrix. 
The pure PES membrane showed the highest water contact angle of $72.4^{\circ}$. The addition of $0.1,0.2,0.3$ and $0.5 \mathrm{wt} \% \mathrm{GO}$ w.r.t. the PES reduced the water contact angle to $64.8,58.1,53.2$, and $52.3^{\circ}$, respectively. This reduction in the water contact angle is caused by the negatively charged oxygen functionalities on the surface of GO and is consistent with the literature $[14,29,30]$. The addition of pore formers alone also reduced the contact angle compared to the pure PES membrane, as previously reported [10]. However, when the pore formers were combined with $0.3 \mathrm{wt} \% \mathrm{GO}$ (M8, M11 and M14), a slight increase in the contact angle was observed compared to the $0.3 \mathrm{wt} \% \mathrm{GO}$ membrane without pore formers (M4). This may be attributed to the effects of the hydrophobic segments of the pore formers as well as the increased surface roughness [31], as shown in the RMS values from Table 2.

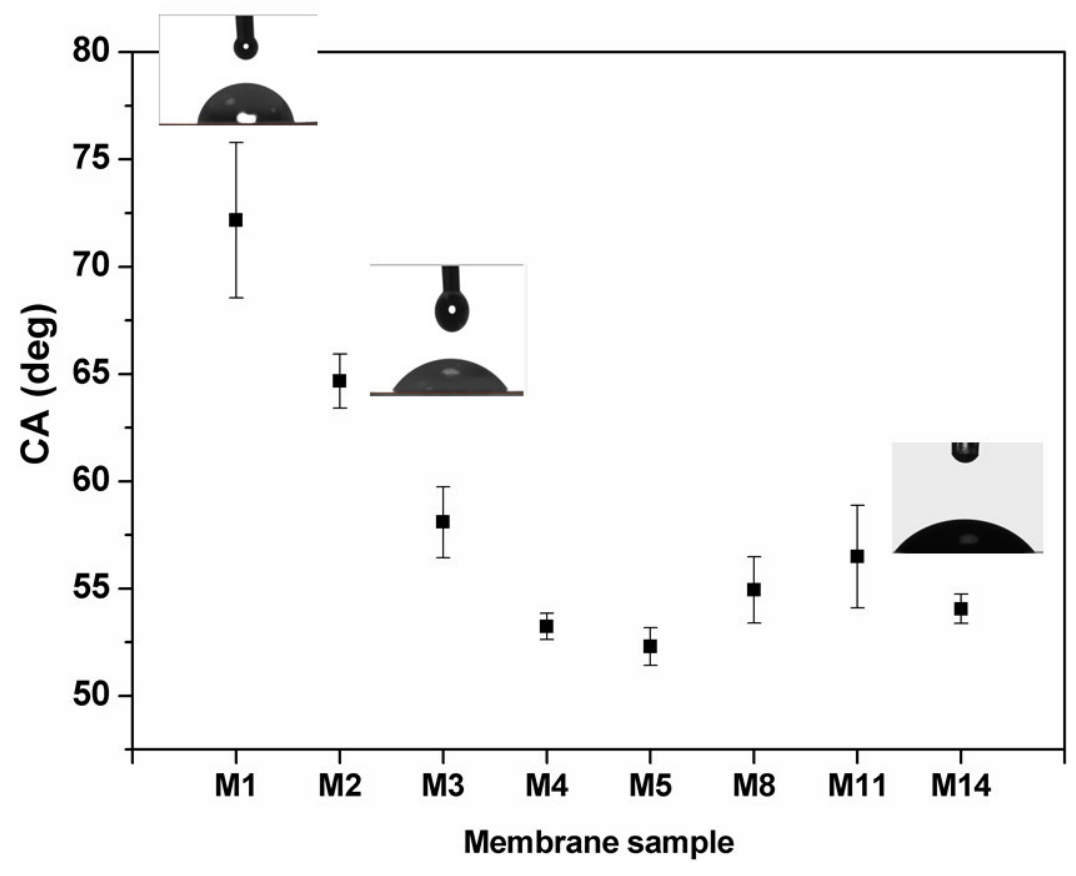

Figure 4. Contact angle of the prepared membranes with entry codes M1-M5, M8, M11 and M14 in Table 1.

To explore the effect of GO on the morphology of PES membranes, cross-sectional SEM images were taken, as shown in Figure 5. The image of the pure PES membrane reveals 
a more dense internal structure and a thicker top skin layer than for the other membranes, which explains the lower flux value shown in section 3.3. As can be seen, the hybrid membranes show no visible agglomerates of GO, indicating that it was well dispersed in the polymer matrix prior to casting. In addition, no cracks are observed on the surface (not shown), indicating that the membranes did not suffer embrittlement by the addition of GO. It is noted that PES/GO MMMs exhibited larger surface pore sizes than pure PES, with this increasing with GO content (M4 and M5). This property is also reflected in the flux data (Figure 7). It is generally well known that the membrane structure induced by the phase inversion process depends on both the rate of outer diffusion of the solvent (DMF) into the coagulation bath and the rate of inner diffusion of the non-solvent (water) into the cast thin film $[32,33]$. The formation of a polymer rich phase is initiated by the demixing process at the time of immersion of the cast film into the coagulation bath. The demixing is driven by the thermodynamic instability between the casting solution and the non-solvent. In this case there is a low affinity of PES to water and thus an instantaneous demixing mechanism takes place. The addition of hydrophilic materials like GO increases the affinity of the polymer solution towards the water. This, in turn, increases the rate of demixing. The formation of varied pore sizes on the membrane surface is due to changes in the diffusion rate of the solvent-non-solvent by the addition of GO on the casting dope solutions. Moreover, GO has a binding affinity with the PES matrix through both hydrogen bonding (Figure 1) and van der Waals forces, which may also increase the demixing rate [26]. 

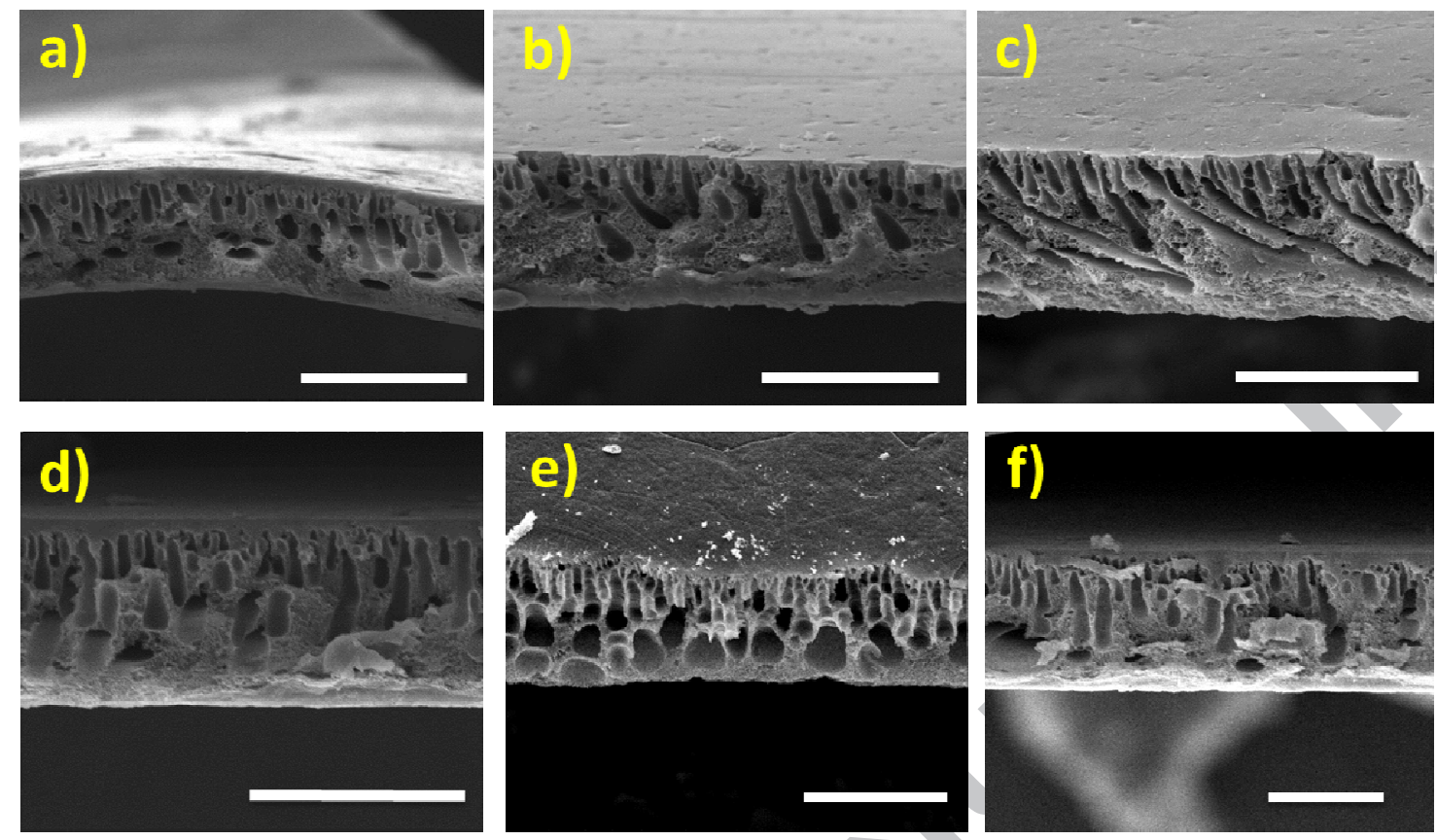

Figure 5. SEM micrographs of the cross section a) M1: PES, b) M4: PES/0.3GO, c) M5: PES/0.5GO, d) M8: PES/0.3GO/3PVP, e) M11: PES/0.3GO/5P31R1, and f) M14: PES/0.3GO/5T904. The scale bars represent 100 $\mu \mathrm{m}$.

The cross sections of PES/GO/pore formers were also examined (membranes M8, M11, and M14). These membranes also have an asymmetric structure consisting of a thin dense top-layer and a porous supporting layer along with fully developed finger-like macrovoids. These are again attributed to the rapid exchange between the solvent and nonsolvent during the phase inversion process, which was promoted by the presence of hydrophilic fillers (i.e. GO, PVP, and T904) [13]. The macrovoids are seen to expand from the surface to the bottom of the membranes. In addition, M11 has less pore continuity than M8 and M14 which may be credited to the increase of dope solution viscosity that retards the exchange rate between solvent and non-solvent during NIPS.

Quantitative analysis of the membrane surfaces was examined using atomic force microscopy. AFM images are shown in Figure 6, while the calculated roughness parameters: 
the root mean square roughness, $R M S$; the average roughness, $R a$, and the mean difference between the highest peaks and lowest valleys, $R z$, are shown in Table 2 . From these data it can be seen that after blending GO into the polymer matrix, the roughness parameters increased. For instance, $R a$ of PES was $23.6 \mathrm{~nm}$ and after adding $0.5 \mathrm{wt} \% \mathrm{GO}$ it increased to $45.2 \mathrm{~nm}$. Also, the addition of pore formers increased the RMS values of the membranes compared to those of the pure PES and GO membranes. These observed increases in surface roughness may be attributed to the faster exchange of solvent and non-solvent occurring during the phase inversion process, owing to the hydrophilic nature of $\mathrm{GO}$ and the pore formers. It has been proposed that a rapid exchange of solvents can lead to the onedimensional shrinkage of surface polymer chains as they respond to the sudden presence of a non-compatible environment (i.e. the non-solvent). This then gives rise to the formation of spheres or nodules of polymer, which can in turn increase the surface roughness [20, 34, 35].

Table 2. Atomic force microscopy data for PES and PES/GO membranes.

\begin{tabular}{llll}
\hline & \multicolumn{2}{l}{ Roughness parameters } & \\
\cline { 2 - 4 } Membrane & Ra (nm) & RMS/Rq (nm) & Rz (nm) \\
\hline M1: PES & 23.6 & 30.7 & 121.4 \\
M3: PES/0.3GO & 30.7 & 39.8 & 201.1 \\
M5: PES/0.5GO & 45.2 & 67.5 & 245.8 \\
M8:PES/0.3GO/3PVP & 71.8 & 90.8 & 302.8 \\
M11:PES/0.3GO/5P31R1 & 54.0 & 74.2 & 234.2 \\
M14:PES/0.3GO/5T904 & 37.2 & 49.7 & 167.8 \\
\hline
\end{tabular}


a)

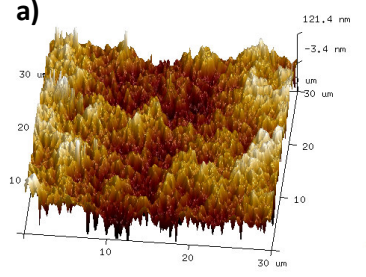

d)

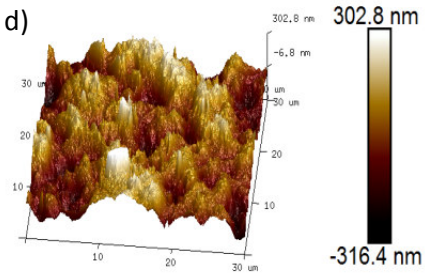

b)
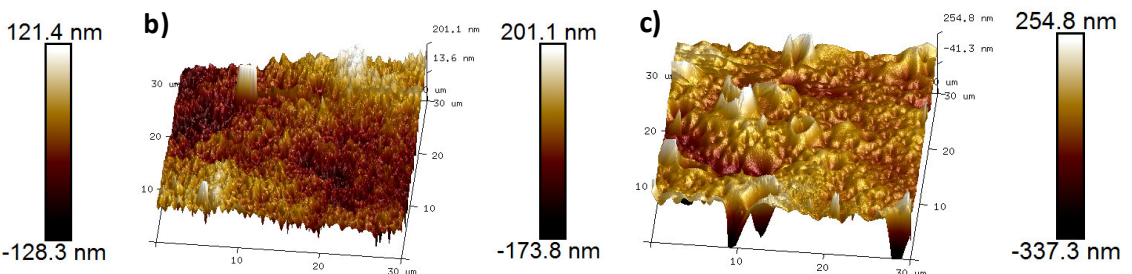

e)

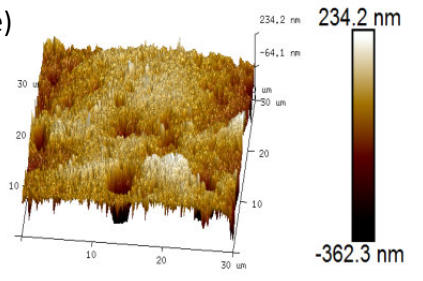

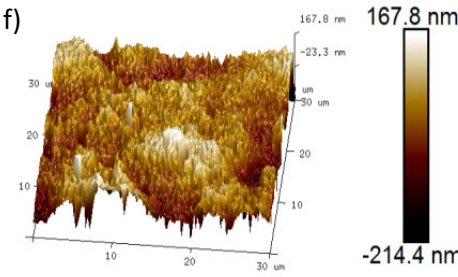

Figure 6. 3D AFM images of PES/GO MMMs with different GO content: (a) Unfilled PES, (b) 0.3\% GO, (c) 0.5\% GO, (d) PES/0.3GO/3PVP, (e) PES/0.3GO/5P31R1 and (f) PES/0.3GO/5T904.

The porosities of the prepared GO/PES ultrafiltration membranes are depicted in Figure 7. It is observed that M1 has the lowest porosity (26\%) but after the addition of 0.1 $\mathrm{wt} \% \mathrm{GO}$, this increased to approximately $70 \%$. This increased again with $0.2 \mathrm{wt} \%$ loading to a peak value of $77 \%$. Above this loading of GO however, the porosity decreased to $66 \%$ with the addition of $0.3 \mathrm{wt} \%$. This can be attributed to trade-off between the thermodynamic and kinetic effects of GO addition. As stated previously, GO, being intrinsically hydrophilic, increases the thermodynamic instability of the polymer system, owing to its greater affinity to the non-solvent (water). This increases the rate of demixing and gives rise to higher porosity. At higher GO loadings, however, the increased viscosity of the casting solutions resulted in greater kinetic hindrance of demixing. This hindering effect became dominant over the competing thermodynamic effect as the GO loading increased and thus, the porosity in membranes M4 and M5 (Figure 7) was lower [26, 36, 37]. Wang et al. [38] reported similar behaviour for GO blended PVDF membranes. It should be noted, that the increased hydrophilicity of the GO/PES membranes may have increased the extent of water penetration 
into the pores during the porosity measurements, giving a higher estimate than for the pure PES membrane. However, the SEM images (Figure 5a \& b) clearly reveal the thicker dense skin layer of the pure PES membrane as well as slightly smaller macrovoids throughout its cross section, compared to the PES/GO membrane. This confirms the marked increase in porosity with the addition of GO despite the effect of better water penetration during gravimetric porosity measurements.

The addition of pore forming agents had an even more significant effect on the membrane porosity than the addition of GO only. Comparing the PES/pore former systems, it can be seen that the porosity increased from $26 \%$ (for pure PES) to $85 \%, 78 \%$ and $81 \%$ for PVP, P31R1 and T904, respectively. However, the highest porosities of all were achieved by combining GO with the pore formers. In the case of PVP and T904 pore formers, the addition of $0.5 \mathrm{wt} \%$ GO resulted in the highest porosity values of $88 \%$ and $87 \%$, respectively. In the case of P31R1, a peak porosity value of $88 \%$ was achieved with the addition of $0.3 \mathrm{wt} \% \mathrm{GO}$. This represents a synergistic effect between GO and the pore formers occurring during the phase inversion process. 


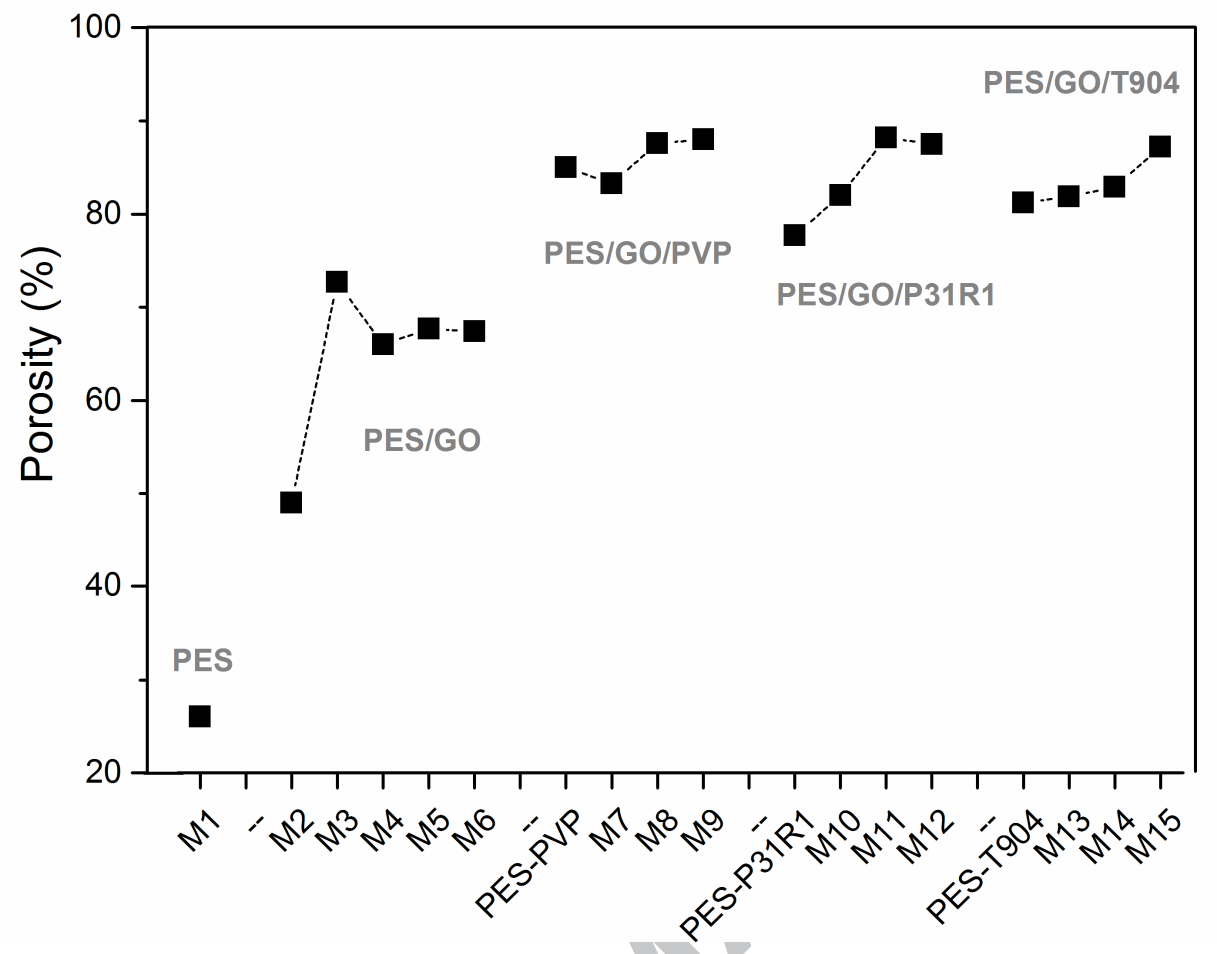

Figure 7. Porosity of the prepared membranes. The $\mathrm{Y}$ axis shows the entry code of the membranes from Table

1. The first value in each of the series marked on the graph as PES/GO/PVP, PES/GO/P31R1 and PES/GO/T904 corresponds to the values of membranes prepared as reported in [10] where PES is blended with just the pore forming agents.

The surface properties of the pure PES and modified PES MMMs were investigated with a static BSA adsorption. This is considered to be one of the dominant factors in determining the membrane fouling properties [39]. Figure 8a depicts the BSA adsorption on the fabricated membranes. The BSA adsorption clearly decreases with the increase in GO loading. In this experiment, M5 showed the lowest BSA adsorption capacity as a result of its increased surface free energy, as seen in Figure 8b. It is important to note that M1 (i.e. pure PES) exhibited a higher contact angle value of $72.4^{\circ}$ which was further reduced to $52.4^{\circ}$ upon the addition of $0.5 \mathrm{wt} \% \mathrm{GO}$ (M5). This may be due to the presence of functional groups such as hydroxyl, carboxyl, carbonyl and epoxy on the surface of GO (Figure 1). This increase in 
the hydrophilicity in turn reduces the protein adsorption. In this way, this experiment shows that membrane surface properties were improved for the hybrid MMMs.

\section{a)}

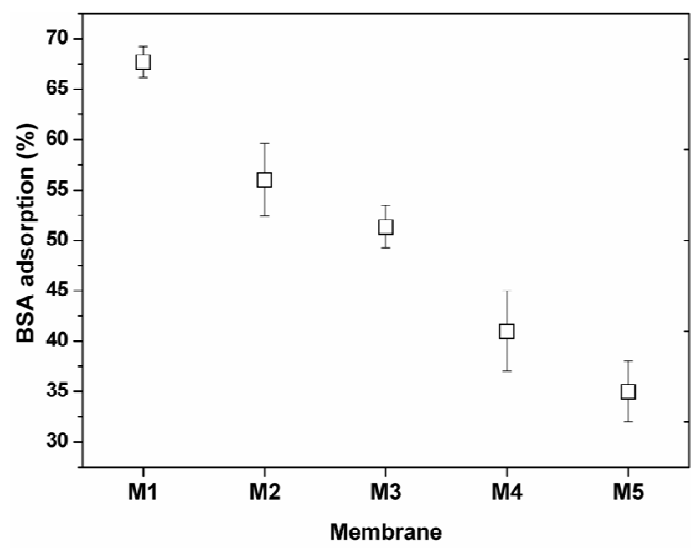

b)

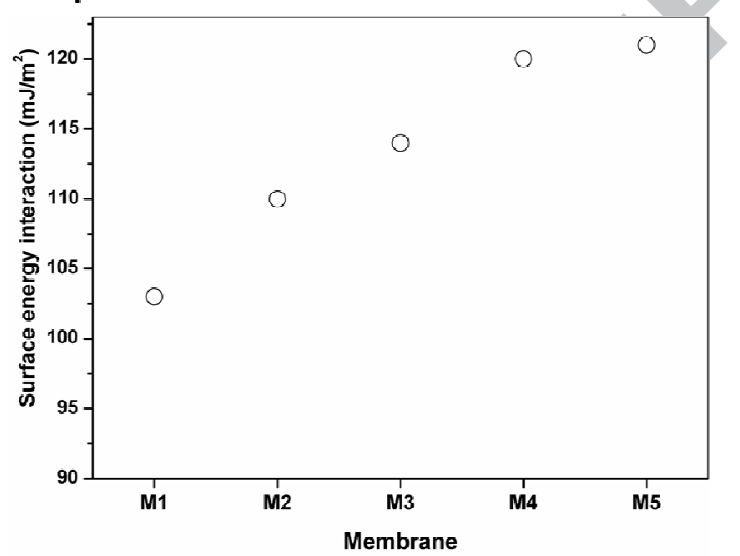

Figure 8. Static adsorption of BSA, and surface energy interaction of the prepared membranes. The $\mathrm{Y}$ axis shows the entry code of the membranes from Table 1.

\subsection{Filtration performance of membranes}

The water permeability of a membrane is a critical factor determining the overall performance of MBR as it affects the fluxes of activated sludge that can be fed into the process [40]. Generally, the pure water permeability (PWP) of a membrane correlates with its hydrophilicity: the more hydrophilic, the higher the PWP (and also the lower the attachment of biomass) [41]. Hence, highly hydrophilic membranes are preferred. In section 3.2 the contact angle measurements of the prepared membranes have shown an increase in hydrophilicity with increased loadings of GO - similar to observations made by Mahmoudi et $a l$ with the addition of silver nanoparticles on graphene oxide nanoplates [29]. All of the nanohybrid membranes yielded a higher PWP than the pure PES membranes due to the synergistic effects between the polymer and the nanofiller. This is in agreement with other 
nanohybrid membranes that have been reported [42]. Remarkably, the PWP of the membranes increased more than six-fold from 2 to $13 \mathrm{LMHbar}\left(\mathrm{L} \mathrm{m}^{-2} \mathrm{~h}^{-1} \mathrm{bar}^{-1}\right)$ for membrane M1, and M5 respectively. However, further loading of GO (1 wt \%) resulted in a dramatic reduction in PWP back to 2 LMHbar, equivalent to the pure PES. This is likely the result of the increased the viscosity of the polymer solution due to high GO loading which reduced the porosity and pore size of the membrane during casting. This result emphasizes the vital role of the hydrophilic nanofillers in contributing to the membrane permeability. This relates to i) the high water holding capacity of the membranes and the ease of transport of water through the membranes due to increased hydrophilicity [26, 43]; ii) the interfacial gaps between GO and the PES polymer matrix, creating additional water channels [44]; and iii) the increase in bulk porosity (Figure 7).

The addition of pore formers PVP, P31R1, and T904 enhanced the PWP values dramatically when compared to M1-M6 membranes (i.e. only GO addition) as is depicted in Figure 9. This is the result of the increased porosities of these membranes (Figure 7) compared to those loaded with GO only. Nevertheless, the highest PWP values were achieved when pore formers and GO were combined. For P31R1 and PVP, it was found that the addition of $0.1 \mathrm{wt} \%$ GO was the optimum loading. While for T904, the optimum GO loading was $0.3 \mathrm{wt} \%$. This may be related to the nature of the additives used and their chemical and physical interactions with the GO and polymer matrix. In general, the PWP for the membranes containing pore formers is much higher than that of the pure PES membrane. PES/GO/T904 with a $0.3 \mathrm{wt} \%$ GO (M14) exhibited the largest PWP value of 245 LMHbar which may be attributed to the increase in hydrophilicity as well pore size and its more open pore structure compared to other membranes. 


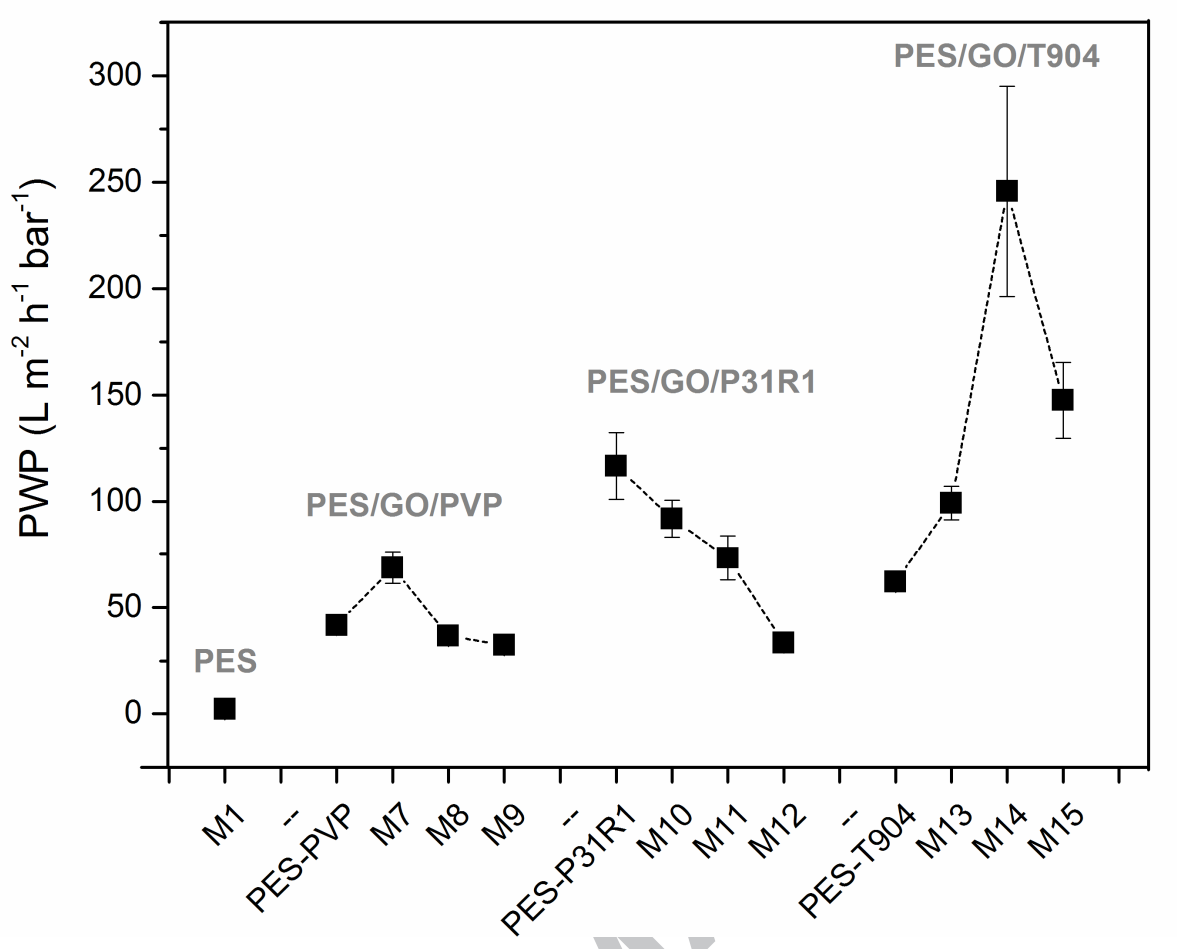

Figure 9. Pure water permeability of the blended PES membranes (distilled water as feed water, $2 \mathrm{hr}$ as operation time, 1 bar applied pressure). The $\mathrm{Y}$ axis shows the entry code of the membranes from Table 1 . The first value in each of the series marked on the graph as $P E S / G O / P V P, P E S / G O / P 31 R 1$ and PES/GO/T904 corresponds to the values of membranes prepared as reported in [10] where PES is blended with just the pore forming agents.

In addition to PWP, the hybrid membranes were tested with an aqueous feed solution containing $1000 \mathrm{ppm}$ of BSA at $\mathrm{pH}=6$. The BSA rejection for the blended membranes with GO was higher than for the pure PES membranes, with a value of $97 \%$ for M6 compared to $\sim 90 \%$ for M1 (Figure 10). Furthermore, the BSA rejection increased substantially with increased GO loading, with and without pore formers. This is likely to be the result of the more negative surface charge caused by the oxygen groups of GO increasing the repulsive force between BSA and the membrane. Two other aqueous solutions containing smaller 
molecules ( $\mathrm{SY}$ and $\mathrm{AO}$ ) were also used as feed solutions and rejection data are presented in Figures 11 and 12 for PES-GO and PES-GO plus pore forming additive, respectively. The SY dye rejection (molecular weight of $458 \mathrm{~g} \mathrm{~mol}^{-1}$ ) was tested and fell in the range of $70-90 \%$ for all PES-GO MMMs (Figure 11 - where membranes M1 to M6 are shown). In addition, the rejection of AO dye (molecular weight of $265.36 \mathrm{~g} \mathrm{~mol}^{-1}$ ) was tested and ranged from 30$50 \%$. Figure 12 shows that the addition of GO to casting solutions containing pore forming agents improved the rejection for BSA and the tested dyes (values of rejection for PES membranes prepared without GO and with pore forming agents as per [10] are shown as well in Figure 12). When compared to the pure PES membrane (M1), rejections of BSA, AO and SY for PES-GO-PVP and PES-GO-P31R1 hybrid membranes increased with the addition of GO. However this trend was not followed by PES-GO-T904 membranes where, at low loadings of GO $(0.1 \mathrm{wt} \%)$ rejections decreased and at a higher loading $(0.5 \mathrm{wt} \%)$ just BSA rejection increased. In any case, these values are abnormally high for ultrafiltration membranes with such low molecular weight dyes. This is an indication of additional interactions between the membrane and the dye which go beyond merely the physical sieving effects and suggests that the prepared membranes show high potential in treating different kinds of wastewater. 


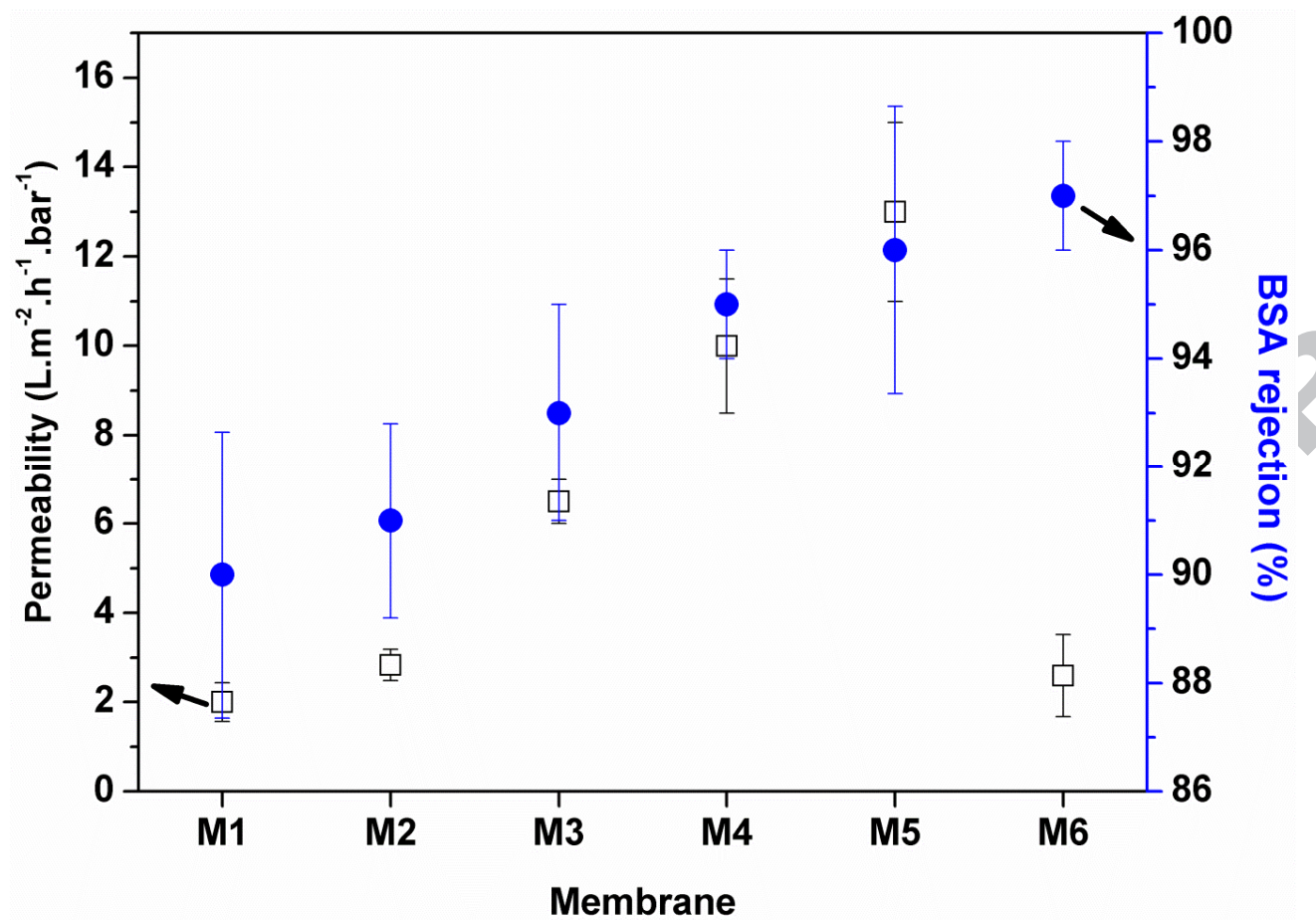

Figure 10 PWP and BSA rejection of the fabricated PES-GO MMMs ( 1 bar, $20^{\circ} \mathrm{C}, 35 \pm 3 \%$ humidity after 30 min at $1 \mathrm{bar}, \mathrm{pH}=6.1 \pm 0.1,500 \mathrm{rpm}$ stirring rate and $1000 \mathrm{mg} \mathrm{L}^{-1} \mathrm{BSA}$ solution). Solid circles represent the BSA rejection and empty squares, the permeability of the membranes.

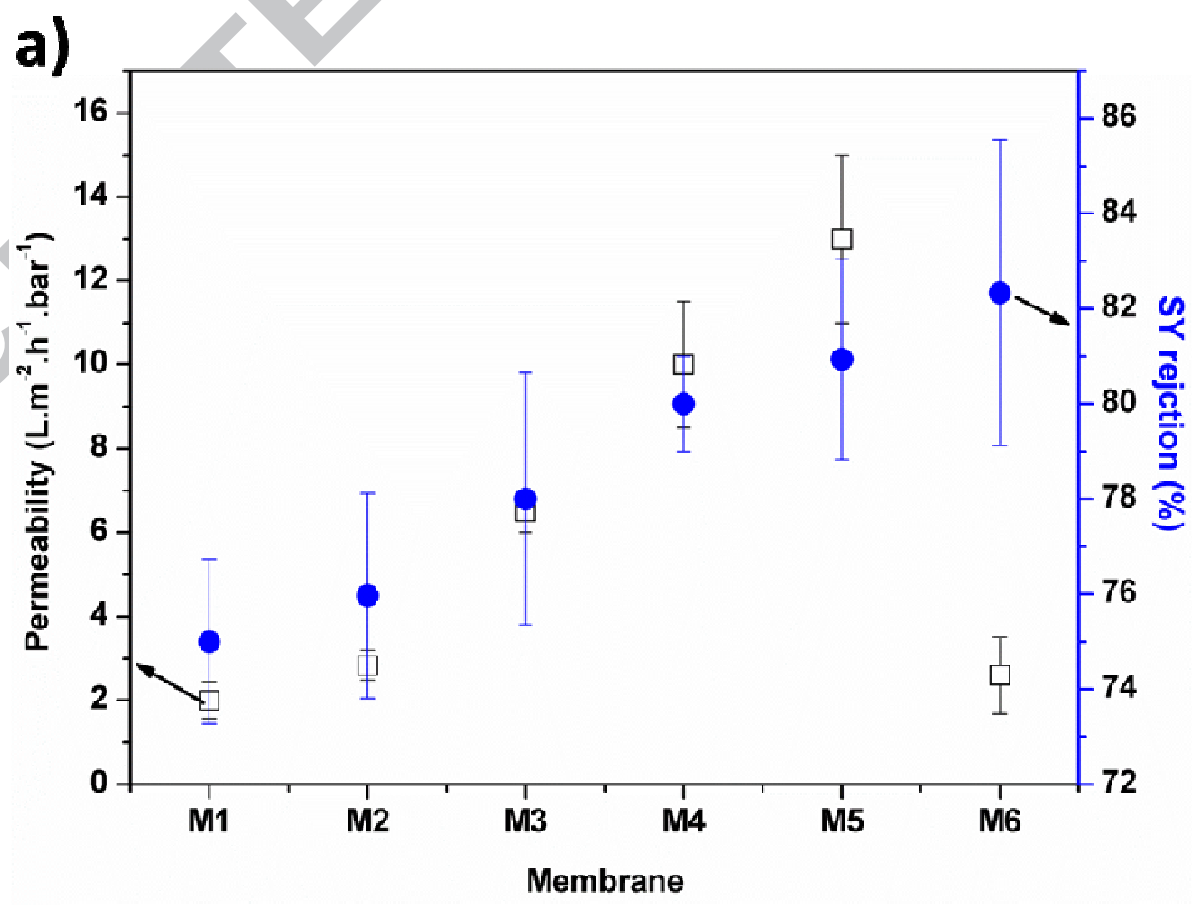




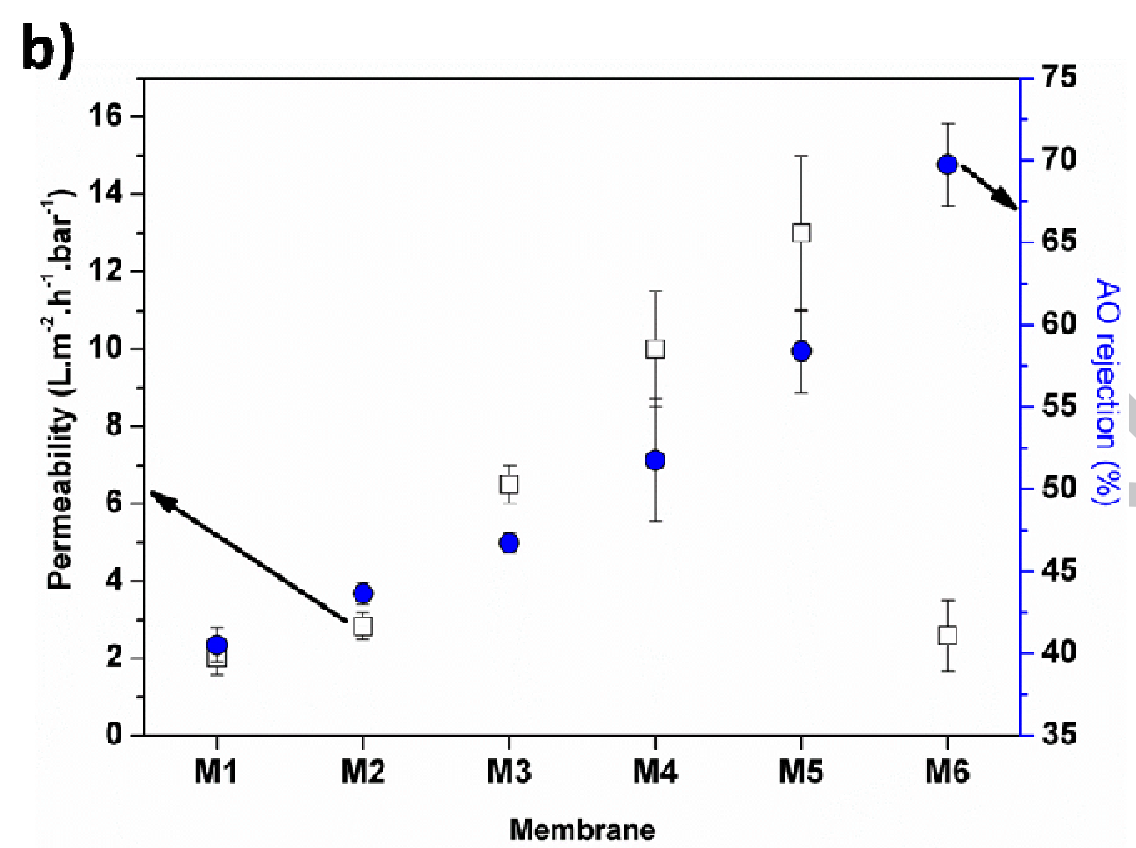

Figure 11. Permeability and dye rejection of PES/GO membranes for (a) sunset yellow and (b) acridine orange (after $30 \mathrm{~min}$ at 1 bar, $500 \mathrm{rpm}$ stirring rate, with a $68 \mathrm{mg} \mathrm{L}^{-1} \mathrm{SY}$ dye solution and a $200 \mathrm{mgL}^{-1}$ AO dye solution). Solid circles represent the dye rejection and empty squares, the permeability of the membranes.

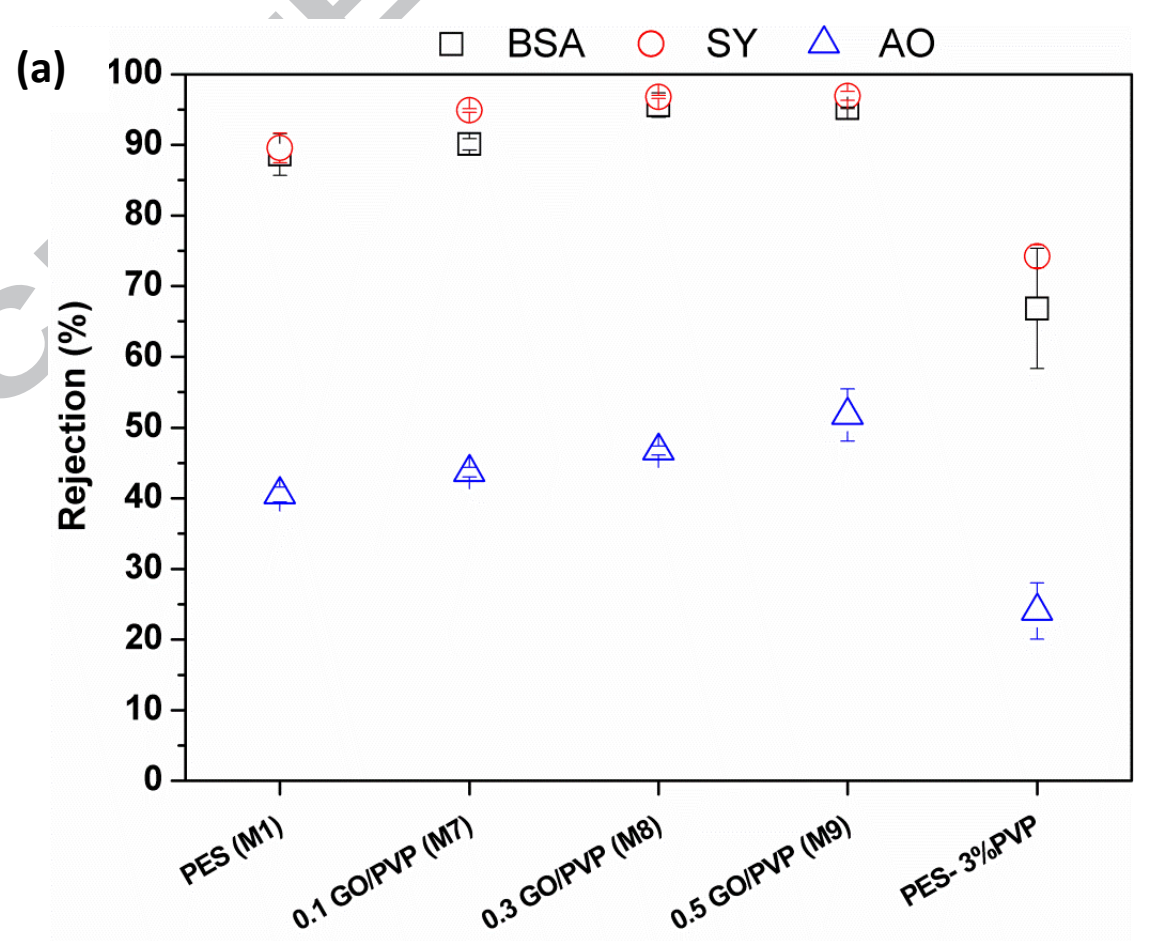


(b)

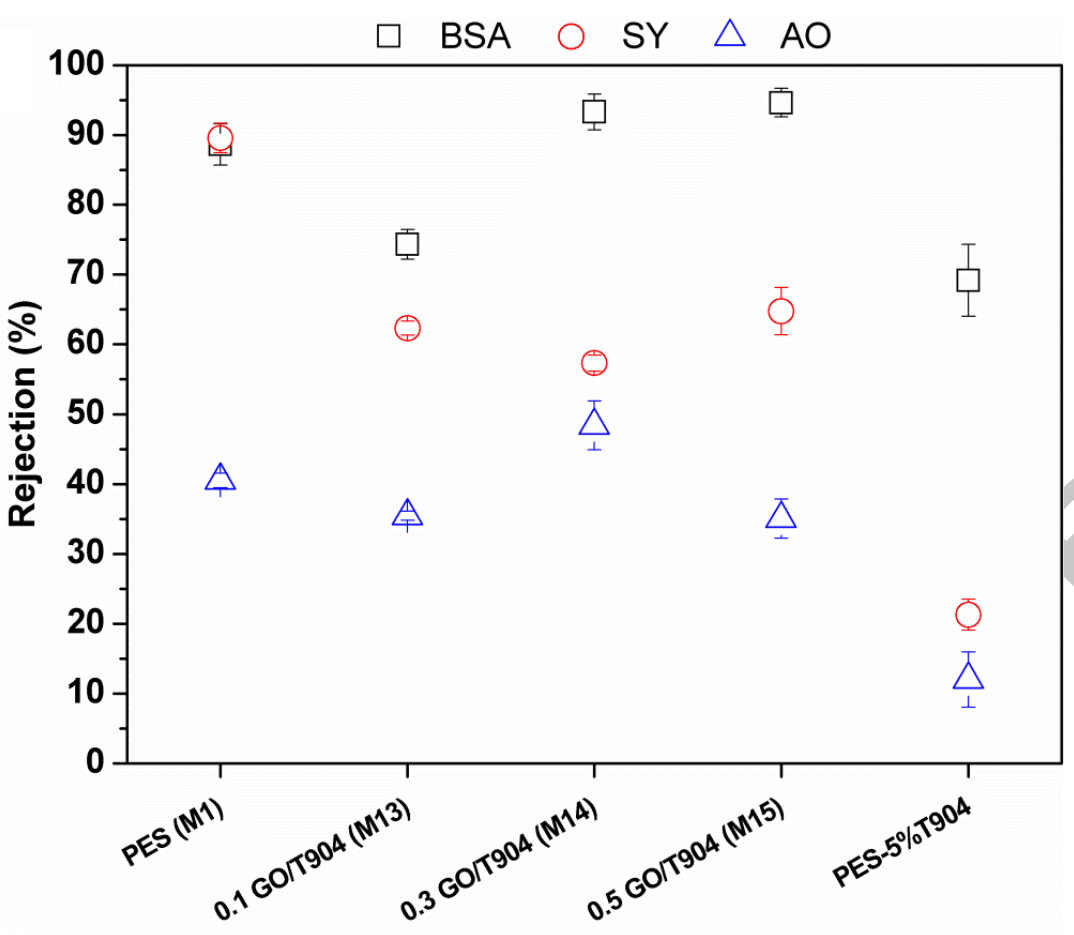

(c)

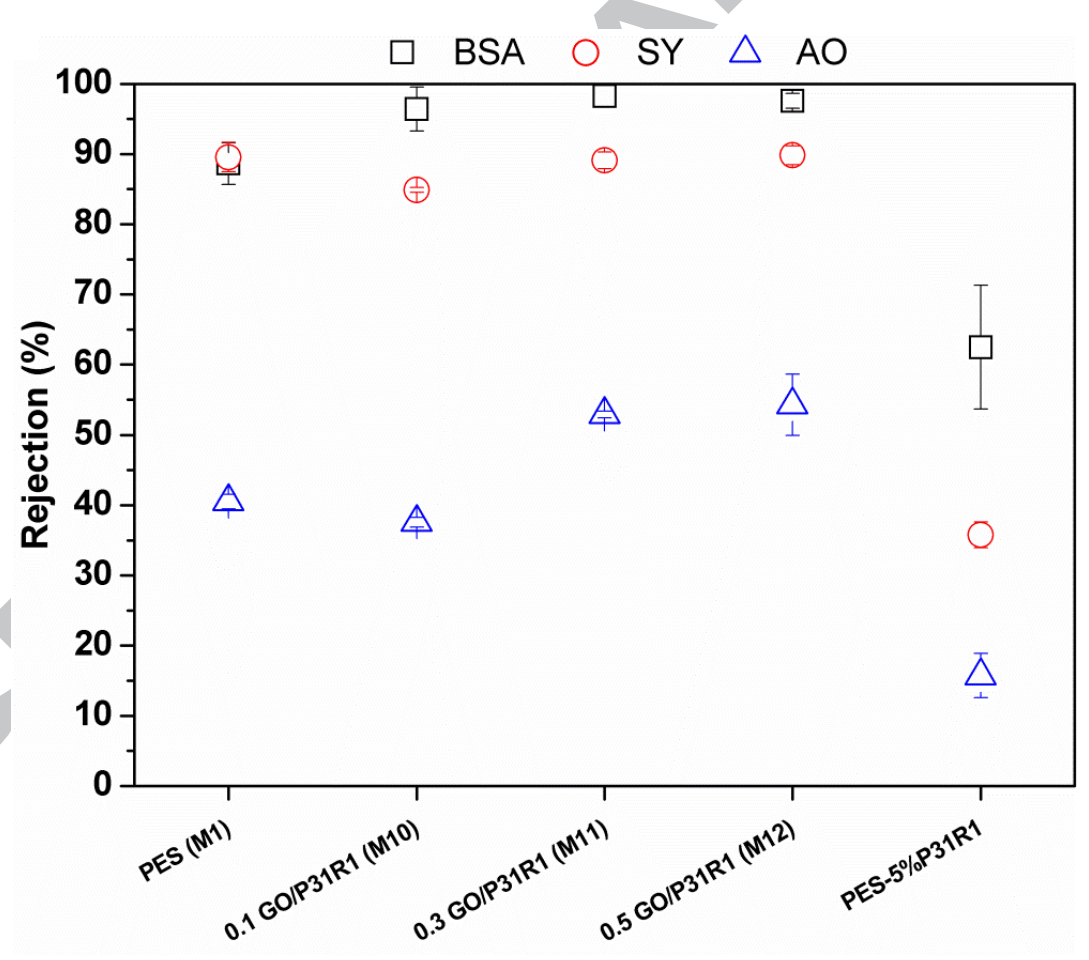

Figure 12. BSA, SY and AO rejection data for the prepared MMMs: membranes containing a) PVP, b) P31R1, and c) T904 as pore forming agents. The last membrane in each of the graphs corresponds to the values of membranes prepared as reported in [10] where PES is blended with just the pore forming agents. 
Membrane fouling is defined in two ways: reversible fouling $\left(R_{r}\right)$, where the adsorption of foulants can be reversed simply by hydraulic cleaning and irreversible fouling $\left(R_{i r}\right)$, where the removal of foulants requires chemical cleaning [45]. The sum of these two parameters gives the total fouling, $R_{t}$. To understand the fouling behaviour of the membranes with BSA solution, $R_{t}, R_{r}$, and $R_{i r}$ values were obtained. These were calculated from the water flux of membranes before and after filtration of 1000 ppm BSA solution with subsequent cleaning with DI water. These values are shown in Figure 13 and $14 . R_{t}$ values for membranes M2-M15 are smaller than that of membrane M1, with the exception of M10. Low $R_{t}$ values indicate that the hybrid membranes have high water flux and improved antifouling properties after UF of $1000 \mathrm{ppm}$ BSA solution. The $R_{r}$ values for the GO membranes were all higher than that for the pure PES membrane, whereas the $R_{i r}$ values were all lower. In the case of the $R_{r}$, a lower value represents reduced attachment of BSA on the membrane surface. The lower values of $R_{i r}$ clearly indicates that the adsorbed BSA on the hybrid membranes can be easily detached by simple cleaning by flushing DI water (also supported by low adsorption values of BSA as depicted in Figure 8). The chance for adhesion or deposition of BSA on the surface of membrane M2-M15 was reduced and loosely attached BSA could be easily removed. Consequently, FRR values of MMMs (depicted in Figure 13) are higher than that of the pure PES membrane (M1), indicating improved antifouling properties [46]. 


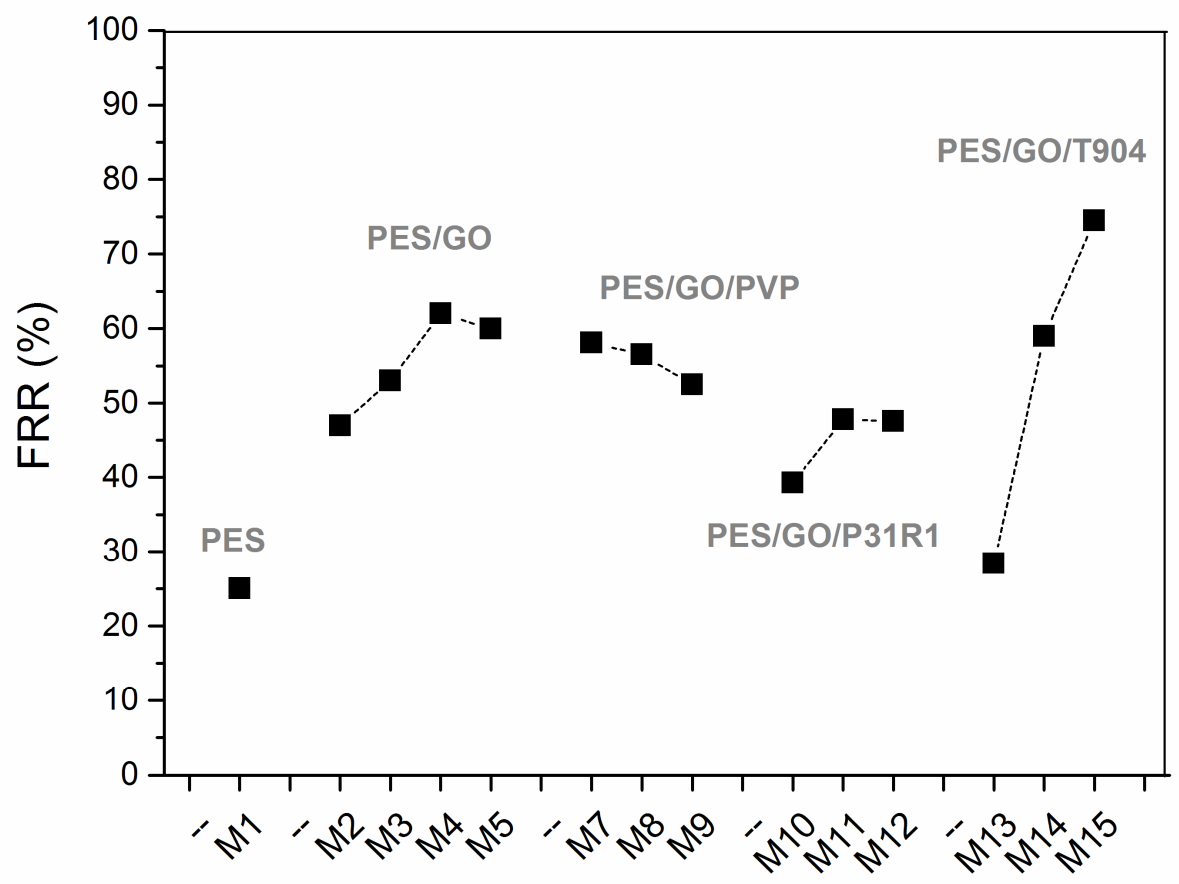

Figure 13. FRR of the prepared membranes. The $\mathrm{Y}$ axis shows the entry code of the membranes from Table 1.

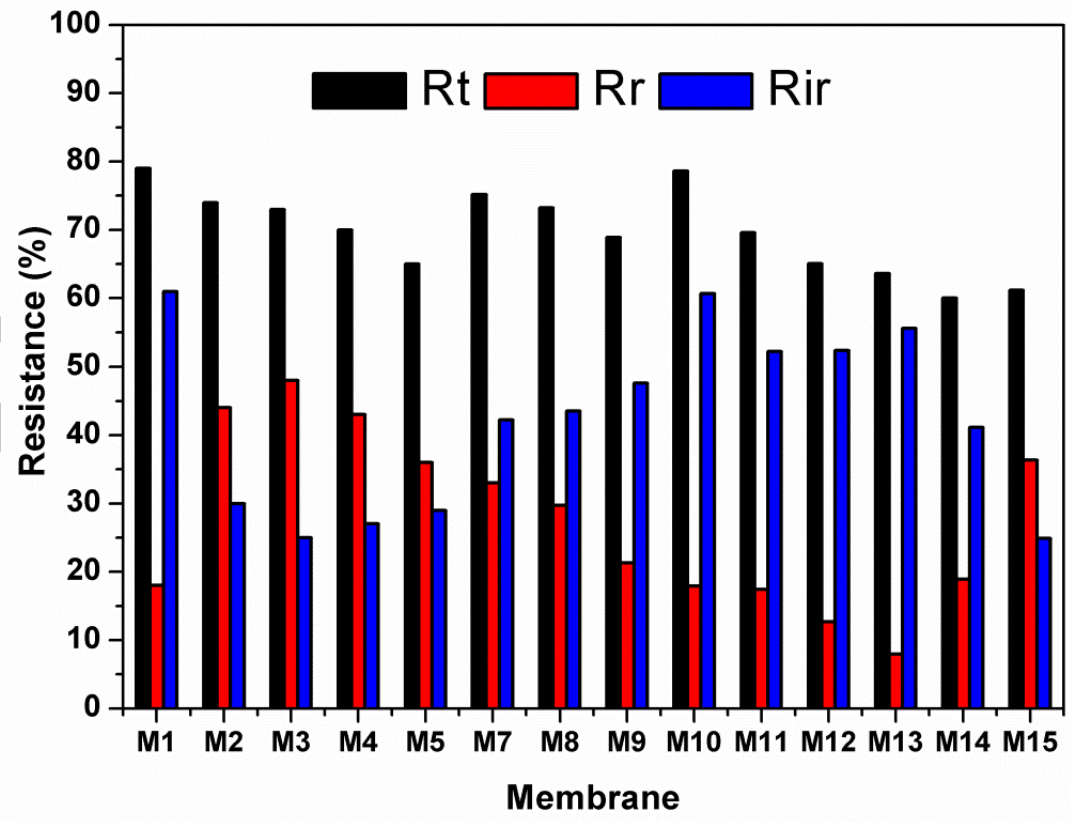

Figure 14. Fouling parameters $\left(\mathrm{R}_{t}, \mathrm{R}_{\mathrm{r}}\right.$ and $\left.\mathrm{R}_{\mathrm{ir}}\right)$ of the prepared membranes. 


\subsection{Comparison with other reported data}

Table S1 in the supporting information illustrates some PWP values of commercially available UF membranes as well as some recent published values of PWP and rejection of graphene-based MMMs. Quite a few polymers blended with different loadings of graphenelike materials have been reported recently for UF applications. From the reported values in the literature, it is worth mentioning the work done by Vatanpour et al. [47] who achieved a PWP of 66.7 LMHbar with MMMs composed of PES and rGO/Ag [48]. Only 0.5\% dodecylamine functionalized multi-walled carbon nanotubes (DDA-MWNTs) increased the PWP six fold compared to bare PSf [49]. The highest value in the literature (110 LMHbar) however, was obtained by Kumar et al. [15] with MMMs of PSF and $\mathrm{GO}-\mathrm{TiO}_{2}$ as filler at a loading of $0.7 \mathrm{wt} \% \mathrm{GO}^{-\mathrm{TiO}_{2}}$. From our results, the hybrid PES/GO/pore former membranes show great potential for UF applications, i.e. very high PWP of up to 245 LMHbar that by far surpass those of commercial polymeric membranes and graphene-based MMMs found in the literature. This is combined with high rejections of BSA, SY dye, and AO dye, with the added advantage of being able to operate at a low pressure of 1 bar. The membrane performance and characterization studies that have been carried out in this work demonstrate that the incorporation of GO leads to the enhancement of membrane performance not just in terms of flux but also anti-fouling properties. From this study, the membrane with the best performance (flux of $245 \mathrm{LMH}$ and reasonable rejections of 74.3, 62.3, and $35.4 \%$ for BSA, SY, and AO, respectively) was achieved with membrane M14 which was prepared with a 0.3 wt $\%$ GO w.r.t. the polymer and 5 wt $\%$ T904 in the casting solution. From the results it can also be concluded that the performance of PES is enhanced by the addition of GO alone (without any pore forming agent). Different characterisation techniques have determined that this improvement is due to a combination of factors such as the homogeneity of the GO 
dispersion in the membranes, increased porosity, increased pore size, and increased hydrophilicity compared to the pure PES membrane. The reasonable rejection properties produced after incorporating only small amounts of GO and/or pore formers ( $>90 \%$ for BSA for membranes with GO and pore forming agents PVP and P31R1, and 35-95\% for SY and AO dyes) are opening an avenue for the utilisation of these MMMs in real applications such as MBRs. In addition, the antifouling results shown by these GO nanohybrid membranes can enhance the process efficiency which can ultimately increase the membrane lifetime and reduce energy and operational costs.

\section{Conclusion}

High permeability and high rejection PES MMMs were successfully fabricated with the incorporation of graphene oxide and various pore forming agents in the polymer dope solution. Such membranes could be employed in membrane bioreactors for effective removal of dyes, proteins and other pollutants from waste water. GO nanosheets, which are hydrophilic in nature due to the abundance of hydroxyl and carboxylic groups, were trapped in the PES matrix after phase inversion. The presence of such fillers enhanced not just the flux but also the rejection behaviour, and the antifouling properties. The membrane contact angle decreased from $72.4^{\circ}$ to $54.1^{\circ}$ while the PWP increased from 2 to $245 \mathrm{LMHbar}$ with

$0.3 \mathrm{wt} \% \mathrm{GO}$ in the membrane and the addition of 5\% T904 in the casting PES polymer solution. The porosity of this membrane also increased significantly to $83 \%$ compared to $26 \%$ for the pure PES membrane. The addition of GO increased the FRR\% to $62 \%$ at a loading of $0.3 \mathrm{wt} \%$ compared to $25 \%$ for pure PES. It was also found that the addition of GO and novel pore formers such as T904 and P31R1, as well as conventional PVP, not only enhanced the permeability but also improved the rejection of dyes and BSA. Hence, it can be concluded 
that the incorporation of GO and pore forming agents into PES membranes has exhibited synergistic effects with increased membrane hydrophilicity, porosity and antifouling properties. This work demonstrates the potential of GO and novel pore formers to enhance waste water treatment technologies such as MBR. Such technology is urgently needed to help control the discharge of dyes and other pollutants into natural water bodies.

\section{Acknowledgments}

The authors are grateful to EPSRC for funding under the grant number EP/K016946/1. Ahmed Abdel-Karim would like to acknowledge the Ministry of Higher Education (MoHE) of Egypt and the Newton-Mosharaffa Fund, Egypt and UK, for providing a scholarship to conduct this study as well as the School of Chemical Engineering and Analytical Science - The University of Manchester for offering all facilities, chemicals, and tools required to do this work.

\section{References}

1. M. A. Shannon, P. W. Bohn, M. Elimelech, J. G. Georgiadis, B. J. Marinas and A. M. Mayes, Science and technology for water purification in the coming decades, Nature 452 (2008) 301-310.

2. D. L. Shaffer, L. H. A. Chavez, M. Ben-Sasson, S. R. V. Castrillon, N. Y. Yip and M. Elimelech, Desalination and Reuse of High-Salinity Shale Gas Produced Water: Drivers, Technologies, and Future Directions, Environ. Sci. Technol. 47 (2013) 95699583. 
3. A. Cassano, C. Conidi and E. Drioli, Comparison of the performance of UF membranes in olive mill wastewaters treatment, Water Res. 45 (2011) 3197-3204.

4. P. Krzeminski, L. Leverette, S. Malamis and E. Katsou, Membrane bioreactors - A review on recent developments in energy reduction, fouling control, novel configurations, LCA and market prospects, J. Membr. Sci. 527 (2017) 207-227.

5. E. Drioli, A. Ali and F. Macedonio, Membrane distillation: Recent developments and perspectives, Desalination 356 (2015) 56-84.

6. R. Sheikholeslami, Fouling mitigation in membrane processes: Report on a Workshop held January 26-29, 1999, Technion - Israel Institute of Technology, Haifa, Israel, Desalination 123 (1999) 45-53.

7. A. G. Fane and C. J. D. Fell, A review of fouling and fouling control in ultrafiltration, Desalination 62 (1987) 117-136.

8. F. Coutte, et al., 10 - Recent Trends in Membrane Bioreactors A2 - Larroche, Christian, in Current Developments in Biotechnology and Bioengineering, M.Á. Sanromán, G. Du, and A. Pandey, Editors. 2017, Elsevier. p. 279-311.

9. $\quad$ M. Ulbricht, Advanced functional polymer membranes, Polymer 47 (2006) 22172262.

10. A. Abdel-Karim, et al., Fabrication of modified polyethersulfone membranes for wastewater treatment by submerged membrane bioreactor, Sep. Purif. Tech. 175 (2017) 36-46.

11. A. A. A.-J. Arsalan Khalid, Othman Charles Al-Hamouz, Tahar Laoui, Zafarullah Khan, Mautaz Ali Atieh, Preparation and properties of nanocomposite polysulfone/multi-walled carbon nanotubes membranes for desalination, Desalination 367 (2015) 134-144. 
12. Y. W. Zhu, et al., Graphene and Graphene Oxide: Synthesis, Properties, and Applications, Adv. Mater. 22 (2010) 3906-3924.

13. J. Lee, et al., Graphene oxide nanoplatelets composite membrane with hydrophilic and antifouling properties for wastewater treatment, J. Membr. Sci. 448 (2013) $223-$ 230.

14. B. M. Ganesh, A. M. Isloor and A. F. Ismail, Enhanced hydrophilicity and salt rejection study of graphene oxide-polysulfone mixed matrix membrane, Desalination 313 (2013) 199-207.

15. M. Kumar, Z. Gholamvand, A. Morrissey, K. Nolan, M. Ulbricht and J. Lawler, Preparation and characterization of low fouling novel hybrid ultrafiltration membranes based on the blends of GO-TiO2 nanocomposite and polysulfone for humic acid removal, J. Membr. Sci. 506 (2016) 38-49.

16. S. Zinadini, A. A. Zinatizadeh, M. Rahimi, V. Vatanpour and H. Zangeneh, Preparation of a novel antifouling mixed matrix PES membrane by embedding graphene oxide nanoplates, J. Membr. Sci. 453 (2014) 292-301.

17. J. J. Song, et al., Ultrathin graphene oxide membranes for the removal of humic acid, Sep. Purif. Tech. 144 (2015) 162-167.

18. J. Zhang, et al., Synergetic effects of oxidized carbon nanotubes and graphene oxide on fouling control and anti-fouling mechanism of polyvinylidene fluoride ultrafiltration membranes, J. Membr. Sci. 448 (2013) 81-92.

19. A. Ammar, A. M. Al-Enizi, M. A. AlMaadeed and A. Karim, Influence of graphene oxide on mechanical, morphological, barrier, and electrical properties of polymer membranes, Arab. J. Chem. 9 (2016) 274-286.

20. J.-H. Choi, J. Jegal and W.-N. Kim, Fabrication and characterization of multi-walled carbon nanotubes/polymer blend membranes, J. Membr. Sci. 284 (2006) 406-415. 
21. T. A. Saleh, M. M. Al-Shalalfeh and A. A. Al-Saadi, Graphene Dendrimer-stabilized silver nanoparticles for detection of methimazole using Surface-enhanced Raman scattering with computational assignment, Sci. Rep. 6 (2016)

22. T. A. Saleh, A. Sari and M. Tuzen, Effective adsorption of antimony(III) from aqueous solutions by polyamide-graphene composite as a novel adsorbent, Chem. Eng. J. 307 (2017) 230-238.

23. M. S. Khan, A. Shakoor, G. T. Khan, S. Sultana and A. Zia, A Study of Stable Graphene Oxide Dispersions in Various Solvents, J. Chem. Soc. Pak. 37 (2015) 6267.

24. D. Y. Kwok and A. W. Neumann, Contact angle interpretation in terms of solid surface tension, Colloids Surf. A 161 (2000) 31-48.

25. M. Alberto, et al., Enhanced organophilic separations with mixed matrix membranes of polymers of intrinsic microporosity and graphene-like fillers, J. Membr. Sci. 526 (2017) 437-449.

26. V. Vatanpour, S. S. Madaeni, R. Moradian, S. Zinadini and B. Astinchap, Fabrication and characterization of novel antifouling nanofiltration membrane prepared from oxidized multiwalled carbon nanotube/polyethersulfone nanocomposite, J. Membr. Sci. 375 (2011) 284-294.

27. C. Chen, et al., Synthesis of Visible-Light Responsive Graphene Oxide/TiO2 Composites with p/n Heterojunction, Acs Nano 4 (2010) 6425-6432.

28. M. M. Lucchese, et al., Quantifying ion-induced defects and Raman relaxation length in graphene, Carbon 48 (2010) 1592-1597.

29. E. Mahmoudi, L. Y. Ng, M. M. Ba-Abbad and A. W. Mohammad, Novel nanohybrid polysulfone membrane embedded with silver nanoparticles on graphene oxide nanoplates, Chem. Eng. J. 277 (2015) 1-10. 
30. R. Mukherjee, P. Bhunia and S. De, Impact of graphene oxide on removal of heavy metals using mixed matrix membrane, Chem. Eng. J. 292 (2016) 284-297.

31. A. L. Ahmad, A. A. Abdulkarim, B. S. Ooi and S. Ismail, Recent development in additives modifications of polyethersulfone membrane for flux enhancement, Chem. Eng. J. 223 (2013) 246-267.

32. X. W. Huang, B. T. McVerry, C. Marambio-Jones, M. C. Y. Wong, E. M. V. Hoek and R. B. Kaner, Novel chlorine resistant low-fouling ultrafiltration membrane based on a hydrophilic polyaniline derivative, J. Mater. Chem. A 3 (2015) 8725-8733.

33. M. Safarpour, A. Khataee and V. Vatanpour, Effect of reduced graphene oxide/TiO2 nanocomposite with different molar ratios on the performance of PVDF ultrafiltration membranes, Sep. Purif. Tech. 140 (2015) 32-42.

34. I. M. Wienk, R. M. Boom, M. A. M. Beerlage, A. M. W. Bulte, C. A. Smolders and H. Strathmann, Recent advances in the formation of phase inversion membranes made from amorphous or semi-crystalline polymers, J. Membr. Sci. 113 (1996) 361-371.

35. B. Vatsha, J. C. Ngila and R. M. Moutloali, Preparation of antifouling polyvinylpyrrolidone (PVP 40K) modified polyethersulfone (PES) ultrafiltration (UF) membrane for water purification, Phys. Chem. Earth 67 (2014) 125-131.

36. S. Qiu, L. Wu, X. Pan, L. Zhang, H. Chen and C. Gao, Preparation and properties of functionalized carbon nanotube/PSF blend ultrafiltration membranes, J. Membr. Sci. 342 (2009) 165-172.

37. H. Susanto, N. Stahra and M. Ulbricht, High performance polyethersulfone microfiltration membranes having high flux and stable hydrophilic property, J. Membr. Sci. 342 (2009) 153-164.

38. Z. Wang, et al., Novel GO-blended PVDF ultrafiltration membranes, Desalination 299 (2012) 50-54. 
39. X. Chen, Y. Su, F. Shen and Y. Wan, Antifouling ultrafiltration membranes made from PAN-b-PEG copolymers: Effect of copolymer composition and PEG chain length, J. Membr. Sci. 384 (2011) 44-51.

40. Y. He, P. Xu, C. Li and B. Zhang, High-concentration food wastewater treatment by an anaerobic membrane bioreactor, Water Res. 39 (2005) 4110-4118.

41. H. H. P. Fang and X. Shi, Pore fouling of microfiltration membranes by activated sludge, J. Membr. Sci. 264 (2005) 161-166.

42. $\mathrm{H} . \mathrm{Wu}, \mathrm{B}$. Tang and $\mathrm{P} . \mathrm{Wu}$, Development of novel SiO2-GO nanohybrid/polysulfone membrane with enhanced performance, J. Membr. Sci. 451 (2014) 94-102.

43. X. T. Zhao, Y. L. Su, H. Dai, Y. F. Li, R. N. Zhang and Z. Y. Jiang, Coordinationenabled synergistic surface segregation for fabrication of multi-defense mechanism membranes, J. Mater. Chem. A 3 (2015) 3325-3331.

44. H. Y. Ma, C. Burger, B. S. Hsiao and B. Chu, Highly Permeable Polymer Membranes Containing Directed Channels for Water Purification, Acs Macro Lett. 1 (2012) 723726.

45. Y.-F. Zhao, L.-P. Zhu, Z. Yi, B.-K. Zhu and Y.-Y. Xu, Improving the hydrophilicity and fouling-resistance of polysulfone ultrafiltration membranes via surface zwitterionicalization mediated by polysulfone-based triblock copolymer additive, J. Membr. Sci. 440 (2013) 40-47.

46. M. K. Sinha and M. K. Purkait, Preparation of fouling resistant PSF flat sheet UF membrane using amphiphilic polyurethane macromolecules, Desalination 355 (2015) 155-168.

47. V. Vatanpour, A. Shockravi, H. Zarrabi, Z. Nikjavan and A. Javadi, Fabrication and characterization of anti-fouling and anti-bacterial Ag-loaded graphene 
oxide/polyethersulfone mixed matrix membrane, J. Ind. Eng. Chem. 30 (2015) 342352.

48. S. Zinadini, V. Vatanpour, A. A. Zinatizadeh, M. Rahimi, Z. Rahimi and M. Kian, Preparation and characterization of antifouling graphene oxide/polyethersulfone ultrafiltration membrane: Application in MBR for dairy wastewater treatment, $\mathbf{J}$. Water Process Eng. 7 (2015) 280-294.

49. A. Khalid, A. A. Al-Juhani, O. C. Al-Hamouz, T. Laoui, Z. Khan and M. A. Atieh, Preparation and properties of nanocomposite polysulfone/multi-walled carbon nanotubes membranes for desalination, Desalination 367 (2015) 134-144. 


\section{Casting solutions}
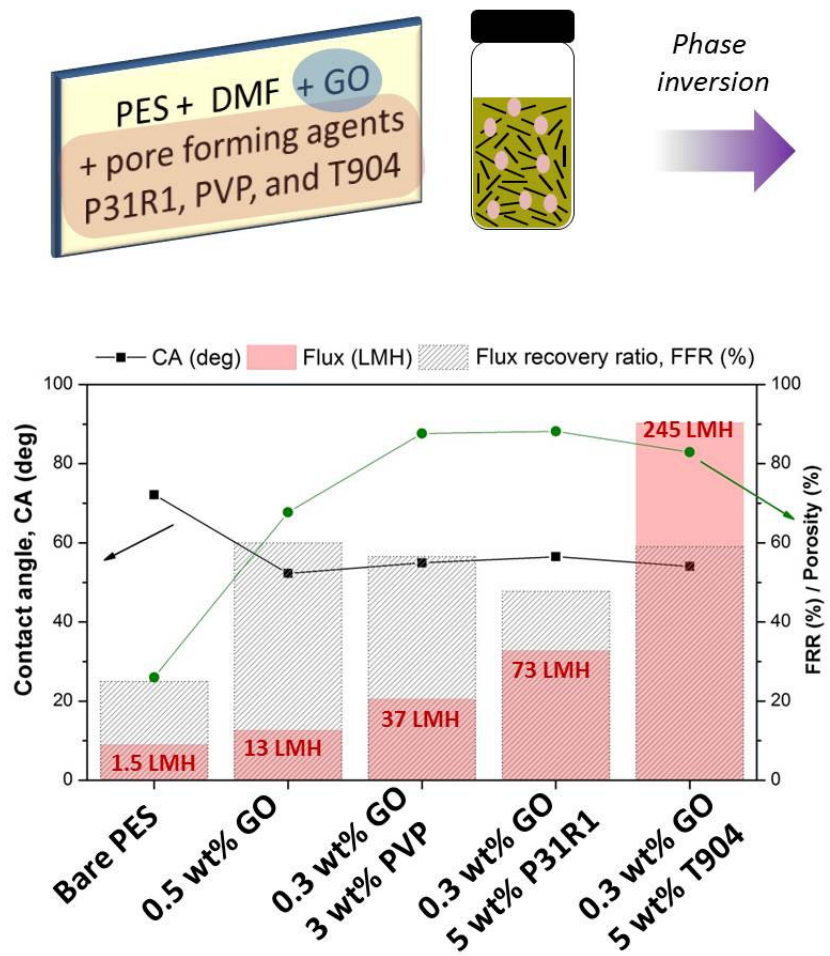

Asymmetric PES/GO MMMs

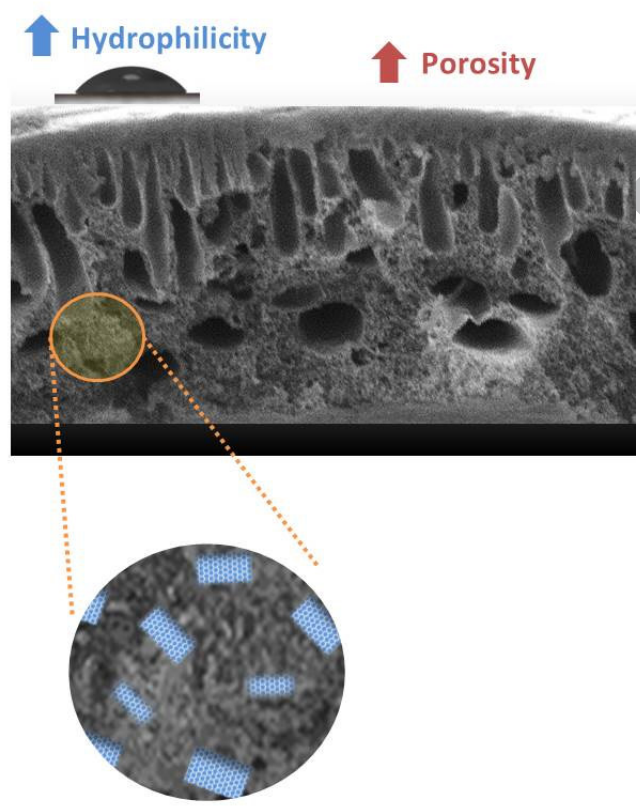


High flux and fouling resistant flat sheet polyethersulfone membranes incorporated with graphene oxide for ultrafiltration applications

Ahmed Abdel-Karim ${ }^{1,4 a}$, Sebastian Leaper ${ }^{1 \mathrm{a}}$, Monica Alberto ${ }^{1}$, Aravind Vijayaraghavan ${ }^{2}$,

Xiaolei Fan ${ }^{1}$, Stuart M. Holmes ${ }^{1}$, Eglal R. Souaya ${ }^{3}$, Mohamed I. Badawy ${ }^{4}$, Patricia Gorgojo ${ }^{1 *}$

\section{Highlights}

5. PES/GO membranes were prepared in combination with various pore forming agents.

6. Higher flux and improved rejection were achieved with the addition of GO.

7. Synthetic solutions of protein and dyes were rejected efficiently at 1 bar.

8. Membrane fouling was reduced with the addition of GO. 